\title{
Assessing gaps and needs for integrating building performance optimization tools in net zero energy buildings design
}

\author{
Shady Attia ${ }^{\mathrm{a}, \mathrm{b}, *}$, Mohamed Hamdy $^{\mathrm{c}}$, William O’Brien ${ }^{\mathrm{d}}$, Salvatore Carlucci ${ }^{\mathrm{e}}$ \\ a Interdisciplinary Laboratory of Performance-Integrated Design (LIPID), Ecole Polytechnique Federale de Lausanne (EPFL), Switzerland \\ ${ }^{\mathrm{b}}$ Université Catholique de Louvain-la-Neuve, Architecture et climat, Louvain-la-Neuve 1348, Belgium \\ c Aalto University, School of Engineering, Department of Energy Technology, PO Box 14400, FI-00076 Aalto, Finland \\ ${ }^{\mathrm{d}}$ Department of Building and Civil E Environmental Engineering, Carlton University, Toronto, Canada \\ e Dipartimento di Energia, Politecnico di Milano, Milan, Italy
}

\section{A R T I C L E I N F O}

\section{Article history:}

Received 8 January 2013

Accepted 19 January 2013

\section{Keywords:}

Simulation-based optimization

Zero energy buildings

Evolutionary algorithms

Needs

Gaps

Review

Interview

\begin{abstract}
A B S T R A C T
This paper summarizes a study undertaken to reveal potential challenges and opportunities for integrating optimization tools in net zero energy buildings (NZEB) design. The paper reviews current trends in simulation-based building performance optimization (BPO) and outlines major criteria for optimization tools selection and evaluation. This is based on analyzing user's needs for tools capabilities and requirement specifications. The review is carried out by means of a literature review of 165 publications and interviews with 28 optimization experts. The findings are based on an inter-group comparison between experts. The aim is to assess the gaps and needs for integrating BPO tools in NZEB design. The findings indicate a breakthrough in using evolutionary algorithms in solving highly constrained envelope, HVAC and renewable optimization problems. Simple genetic algorithm solved many design and operation problems and allowed measuring the improvement in the optimality of a solution against a base case. Evolutionary algorithms are also easily adapted to enable them to solve a particular optimization problem more effectively. However, existing limitations including model uncertainty, computation time, difficulty of use and steep learning curve. Some future directions anticipated or needed for improvement of current tools are presented.
\end{abstract}

(c) 2013 Elsevier B.V. All rights reserved.

\section{Introduction}

During the coming years, the building design community at large will be galvanized by mandatory codes and standards that aim to reach net zero energy buildings (NZEBs) [1-3]. The recast of the European Performance of Buildings Directive (EPBD) requires all new buildings to be "nearly zero energy" buildings (nZEB) by 2020, including existing buildings undergoing major renovations. As building performance objectives become more ambitious

Abbreviations: AEC, architectural, engineering, construction; ACOA, ant colony optimization algorithm; BPO, building performance optimization; BPS, building performance simulation; DOE, Department of Energy; EPBD, energy performance building directive; GA, genetic algorithms; GUI, graphical user interface; HVAC, heating, ventilation and air conditioning; IBPSA, international building performance simulation association; IEA, international energy agency; NSGA, non-dominated sorting genetic algorithm; NREL, national Renewable Energy Laboratory; nZEB, nearly zero energy building; NZEB, net zero energy building; MPC, model predicted control; SQP, sequential quadratic programming; WWR, window-to-wall ratio.

* Corresponding author at: EPFL-ENAC-IA-LIPID, Station 16, Lausanne 1015, Switzerland. Tel.: +41216930 878; fax: +41216930885.

E-mail addresses: shady.attia@epfl.ch (S. Attia), Mohamed.hassan@tkk.fi (M. Hamdy), liam_obrien@carleton.ca (W. O’Brien), Salvatore.carlucci@polimi.it (S. Carlucci). and absolute, the number and complexity of energy use-reducing measures, implemented in design, and tend to increase $[3,4]$. The building performance objectives have raised the bar of building performance, and will change the way buildings are designed and operated. This means that evaluating different design options is becoming more arduous than ever before. The building geometry, envelope and many building systems interact, thus requiring optimizing the combination of the building and systems rather than merely the systems on an individual level [5]. One promising solution is to use automated mathematical building performance optimization (BPO) paired with building performance simulation (BPS) as a means to evaluating many different design options and obtain the optimal or near optimal (e.g., lowest life-cycle cost, lowest capital cost, and highest thermal comfort) while achieving fixed objectives (e.g., net zero energy) [6-10].

Despite optimisation's potential in NZEB design, it largely remains a research tool and has yet to emerge in common industry practice. As this paper reports, major obstacles to BPO in industry include lack of appropriate tools, lack of resources (time, expertise), and the requirement that the problem be very well defined (e.g., constraints, objective function, and finite list of design options). The objective of this paper is to document the current state-ofthe-art in terms of NZEB optimization tools and practice. With 
this information disseminated, it is anticipated that software developers will be better informed of the needs of building design processionals.

Major components of the paper include a literature review of more than 150 publications on BPO and existing optimization tools, followed by the results of an interview that was used to gain an understanding of how people currently use optimization tools, which tools they use, the major limitations they have encountered, and their vision for the future of optimization. A qualitative study design was employed, using semi-structured interviews. Optimization experts working in academia or practice were recruited. Experts were identified as researcher or professional who has at least three or more publications in the field of BPO. The participants were identified from the IBPSA International and Regional Conference Proceedings between 1995 and 2010 [11]. A sampling framework was developed to include experts in the study from Asia, Europe and North America. These groups represented the range of possible optimization users, from researchers and designers considering optimization in the design of net zero or high energy performance buildings. A list of potential optimization experts was created (40 potential experts) and circulated between the IEA Task 40 Subtask members [3]. Every interviewed expert was asked to revise the list and add any potential candidate to be interviewed. Recruitment continued until experts from different countries had been represented and thematic saturation had been attained for the sample as a whole. An additional group of experts had been invited during IBPSA 2011 Conference in Sydney. In total, 28 experts were interviewed between January and November 2011.

The interview questions were formulated by the authors and classified under five categories namely, background, methodology, output, integration in design and shortcomings and needs. The questionnaire aimed to probe the user's experience with computational optimization tools and techniques for the design of NZEBs. Prior to interviewing the experts, the authors set up a pilot study to tests and improve the questionnaire reliability and internal validity. Comments and suggestions were requested from peer reviewers. Reviewers were asked to revise the questionnaire and provide critical feedback in order to optimize the clarity and relevance of the questionnaire.

The scope of the study is limited to nZEBs, NZEBs and high energy performance buildings. Those building types are emerging as a quantifiable design concept and promising solution to minimizing the environmental impact of buildings sector. These buildings, which minimize energy consumption and optimally use renewable resources, both passively and actively are usually defined as those which export as much energy as they import, over the course of a year (also known as net zero site energy by Torcellini et al. [12]. The term 'net zero' is used for identifying those buildings connected to the grid. The grid is used both as an ideal source and an ideal storage medium and energy losses are not taken into during the energy supply from the grid to the building, and the energy feeding from the building into the grid. The issues of modelling, design and optimization of such buildings are being addressed by Subtask B (STB) of the IEA SHC Task 40/ECBCS Annex 52 [1].

Key results of the interview indicate that optimization tools that do exist are primarily catered to research, and consequently, they do not reflect the needs of industry (fast turn-around, high return on invested time, ease of use, shallow learning curve, userfriendly interfaces). Some future directions anticipated or desired by those who were surveyed faster computing (e.g., cloud computing and real-time feedback of results), improved visualization of results, improved methodologies (e.g., automated error-checking, validation, and uncertainty analysis) and standardized costs and performance databases.

This paper is organized into six sections. The first section identifies the research problem within the BPO community. The second section is a literature review that defines the simulation based BPO and illustrated various related studies, methods and tools to support it. The literature review forms the basis for the interview questions. The interview results and analysis are discussed in Sections 3 and 4 . The final two sections are discussing the interview findings and providing feedback to tool developers and to the architectural, engineering and construction communities.

\section{Literature review}

This section presents the state-of-the-art with respect to building design optimization tools and optimization algorithms coupled to building simulation tools. The content is intended to aid the reader in better understanding areas of active research in building optimization as well as tools and methods commonly used by researchers and industry.

\subsection{What is $B P O$ ?}

Automated building performance optimization is a process that aims at the selection of the optimal solutions from a set of available alternatives for a given design or control problem, according to a set of performance criteria. Such criteria are expressed as mathematical functions, called objective functions. Automated optimization is a combination of different types of optimization algorithms, setting each algorithm to optimize one or various design functions. The optimization objectives are to identify the cost or energy or environmental impacts.

Therefore, an objective function is defined as a mathematical function subjected to optimization. Optimization is a process that searches for the optimal solution with respect to the objective functions to be maximized or minimized, possibly subjected to some constraints of the dependent variables. If the constraints are not specified, the problem is denoted unconstrained optimization problem. A constraint limits the problem space to a subset of elements [13]. If the optimization problem aims at minimizing a single objective function, it is called single objective optimization problem, otherwise if the objective functions are more than one, it is called multi objective optimization problem.

Visualization techniques are essential to facilitate the extraction of relevant information regarding performance trade-offs, propagation of uncertainties and sensitivity analysis. By allowing for visualization during the optimization process, it is possible for the designer to interact and inform the optimization process.

\subsection{Brief history of $B P O$}

Automated optimization has become increasingly popular in a wide variety of application domains, as reflects a book entirely devoted to this topic [14]. In the late 1980s, a large group of technologically savvy engineering, mathematics and scientific groups tackled the application of automated optimization in the field AEC industry aiming to optimize building design and operation. By the end of 1990s decade, many scientific groups that have well-used BPS made a transition and coupled their simulation work to mathematical optimization models. Through the 2000s, the development of mathematical and algorithmic techniques and the advancement of BPS tools gave way to BPO tools that could solve multi objective optimization problems of a design. Mechanical and structural engineers working on complex buildings have been among the early adopters of BPO techniques, but architects and other engineers now start using these techniques as well. Today, there is a strong trend towards population-based search algorithms such as evolutionary algorithms and particle swarms. These algorithms have been proven to be very successful in optimizing one or many performance criteria while handling search 
constraints for large design problems [15-17]. It has now become common practice for populations of building simulations to be carried out simultaneously on multi-core processors and distributed computing to greatly reduce the time needed for an optimization study (GenOpt [18], modeFrontier [19], and Phoenix Integration [20]). Researchers have found success in combining deterministic searches and population-based searches to improve search resolution and the reproducibility of optimal solution sets in building design problems.

\subsection{Importance of $B P O$}

In the architectural, engineering and construction (AEC) industry there is a growing research trend for automated optimization approaches to be used to map out and find pathways to buildings designs with desirable qualities, be it aesthetics, geometry, structure, comfort, energy conservation or economic features, rather than focusing on one particular outcome. Although optimization studies are most commonly performed in the early-design stage, where the majority of design decisions have yet to be made, optimization approaches can be equally useful in the late-design stages for selecting and fine-tuning control strategies and HVAC design and during building operations to best select building control based on model-predictive control strategies [21-24]. The most appropriate search algorithms and modelling approaches vary depending on the application area, but the suitable application area for optimization methodologies related to building design and control is vast and constantly evolving.

Moreover, the use of optimization as a means of providing input to energy policy, incentive measures is one of its most important usages in the recent years. For example, using the building energy optimization model (BEopt) developed by the national renewable energy laboratory (NREL) to evaluate the energy and cost savings potential from constructing more efficient new homes and net zero-energy homes in the USA [25]. Also this includes the call of the European Commission for implementing a methodology to calculate cost-optimal levels in the EPBD framework. European Member States are required to define cost-optimal levels of minimum energy performance according to their specificities [26].

\subsection{Combination of $B P O$ and simulation}

Inevitably, optimization is coupled to BPS tools. BPS tools are essential in the process of building design aiming to assess their energy performance, environmental impacts, costs, etc. [27,28]. A number of energy simulation engines exist and are often used in different stage of the design process of a building $[29,30]$. Out of the 406 BPS tool listed on the DOE website in 2012, less than 19 tools are allowing BPO as shown in Table 1 and Fig. 1 [31-33].

When designers decide to improve the building performance, they usually make estimation for various values of the design variables to be modified in the building envelope, the heating ventilating and air-conditioning (HVAC) system and the types of energy generation and run the simulation many times. Then, designers will try to find the effect of the design changes on the simulation results and to conclude a relation between those variables and the objectives of the simulation. This is an inefficient procedure in time and labour. Besides, the relation between the simulation variables and the objectives may not be simply understood, especially when there are many parameters to be studied, and possibly due to the nonlinearity of the problem. Therefore a better design is not always guaranteed. To overcome such difficulties, automated simulation based BPO search techniques are applied. Progressions in building simulation tool development and in coupling complimentary BPS tools at run-time expand domains where BPS optimization studies can occur.
In order to automate and make more efficient the testing and comparison of several design building variants, a number of researchers have coupled energy simulation tools with optimization techniques through self-produced tools, commonly based on MATLAB $^{\mathrm{TM}}$ [34], or other dedicated software [35].

\subsection{Optimization design variables}

The most common design variables in BPO studies are either energy related or economic related. Multiple objectives can simultaneously be considered through weighting strategies or by using a multi-objective optimization algorithms which preserves tradeoffs between two or more conflicting search objectives [36]. Before conducting an optimization search, first the designer must identifying which input design variables should be included in the optimization search. Designers can perform a sensitivity analysis to identify which inputs have the largest impact on an objective. An alternative is to refer to previous research to aid in identifying influential input variables. In the recent years, several studies applied BPO techniques in order to optimize a specific aspect of the building design or operation. A list follows disaggregated by the objective of the optimization:

- Building layout and form [37-41].

- Geometry, position and density of fenestration [42].

- Building envelope and fabric constructions [15,43-51].

- Daylighting performance $[52,53]$ and automated control of solar shadings [54,55].

- Natural ventilation strategies [56,57].

- Shape and functional structure of buildings as well as heat source utilization [58].

- Heating, ventilating, and air-conditioning (HVAC) systems sizing [59-63].

- HVAC system control parameters and/or strategy [64-68].

- Thermal comfort [69-75].

- HVAC system configuration synthesis [76,77].

- Managing of energy storage $[78,79]$ and automated model calibration $[80,81]$

- Simultaneous optimization of building envelope and HVAC elements [7,15,16,65,82-90].

- Simultaneous optimization of building construction, HVACsystem size, and system supervisory control [91-93].

- Simultaneous optimization of building construction, HVAC elements and energy supply system including RES [94-98].

Also several $\mathrm{PhD}$ work approached BPO including the work of Caldas [99], Nielsen [100], Wetter [101], Wang [102], Pedersen [103], Verbeeck [104], Choudhary [105] and Hopfe [106].

However, there are significant disparities between the above BPO applications. Some of them apply multi-objective optimization while the others do single objective ones. The implemented optimization algorithms range from enumerative to stochastic ones. The size and complexity of the addressed solution spaces are quite different. Some studies used detailed BPS tools while others used simplified ones. In order to reduce the simulation time, three strategies are common:

- Custom simplified thermal model are developed and used instead of existed detailed BPS software [77,100,107-109].

- Detailed BPS tools are used for simulating geometrically simplified models: e.g. a single zone model is used for representing one floor single family house [85], a two zones model for a twostory house [17], a simplified model for representing a $200 \mathrm{~m}^{2}$ house [110], and two representative zones are used to evaluate the thermal performance of one floor in office building [111]. 
Table 1

Classification of BPO tools.

\begin{tabular}{|c|c|c|c|c|}
\hline & Simulation based optimization & Optimization packages & & Tailor made-programming \\
\hline \multirow[t]{4}{*}{ Public } & TRNOPT (2004) & & & \\
\hline & BeOpt (2005) & & & \\
\hline & OptiMaison (2005) & & & \\
\hline & OptiPlus (2006) & & & \\
\hline \multirow[t]{6}{*}{ Private/commercial } & ARDOT (2002) & MATLAB optimization toolbox (1990) & Topgui (1990) & $\mathrm{C}++$ \\
\hline & Polysun (2006) & Phoenix integration (1995) & GenOpt 2001 & Cygwin \\
\hline & GENE_ARCH (2008) & GAlib (1995) & Paradiso EO 2003 & Java \\
\hline & Lightsolve (2008) & modeFrontier (1999) & ThermalOpt 2011 & $\mathrm{R}$ \\
\hline & ParaGen (2011) & Homer (2000) & & Visual Studio \\
\hline & ZEBO (2012) & DER-CAM (2000) & & \\
\hline
\end{tabular}

- Detailed BPS tools are used for simulating a model only for a representative period: e.g., few days are used as a weather samples $[112,113]$ and 6 months is used as a representative period [111] for the whole year weather conditions (temperature, humidity, wind speed and solar radiation).

\subsection{BPO objectives (single-objective and multi-objective functions)}

Generally speaking, optimization can be either single-objective or multi-objective according to the number of objective functions that define the optimization problem. In the case of optimizing a single-objective function, an optimum solution of the problem is either its global maximum or minimum, depending on the purpose. In general, it is a convention in mathematical optimization, that optimization problems are commonly defined as minimizations of the quantity, instead, if an optimization problem consists in the maximization of an objective function, it is sufficient to minimize its opposite [114]. In many real problems, it is required to satisfy simultaneously more than one objective function. Such problems are denoted multi-objective optimization problems.

In multi-objective optimization problems, a single solution could not be able to minimize (or maximize) simultaneously each objective function. Rather, when searching for solutions, one comes to limit variants such that, a further improvement towards the minimum value of one of the objective function causes a worsening of the closeness to minimum of the others. Therefore, the aim of a multi-objective optimization problem consists in finding such variants and possibly in quantifying the trade-off in satisfying the individual objective functions. The role of the optimization algorithm is to identify the solutions which lie on the trade-off curve, known as the Pareto Frontier, which is in words, a set of optimal solutions plotted in the form of a curve (named after the ItalianFrench economist, Vilfredo Pareto, see Fig. 10.5). These solutions all have the characteristic that none of the objectives can be improved without prejudicing another. The variants of a Pareto Frontier are defined as elements that are better than others in relation to, at least, one objective function and simultaneously not worse concerning all other objective functions.

\subsection{Algorithms used in $B P O$}

Optimization of a building as a whole is a complex problem due to the amount of design variables as well as the discrete, non-linear, and highly constrained characteristics. The popular optimization methods for solving multi-objective optimization problems are generally classified into three categories: (1) enumerative algorithms, (2) deterministic algorithms, and (3) stochastic algorithms.

The enumerative methods search in a discrete space. They evaluate all the solutions and choose the best. These algorithms are computationally expensive and consequently they are not suitable for exploring wide solution spaces. Two types of methods can be found: (1) gradient and (2) gradient-free deterministic. The gradient ones use the gradient of the evaluation functions either by going in the direction where the gradient is the smallest or by searching solutions that have a gradient vector equal to zero. The gradient-free ones such as Hooke-Jeeves direct search [115], constructs a sequence of iterates that converge to a stationary point if

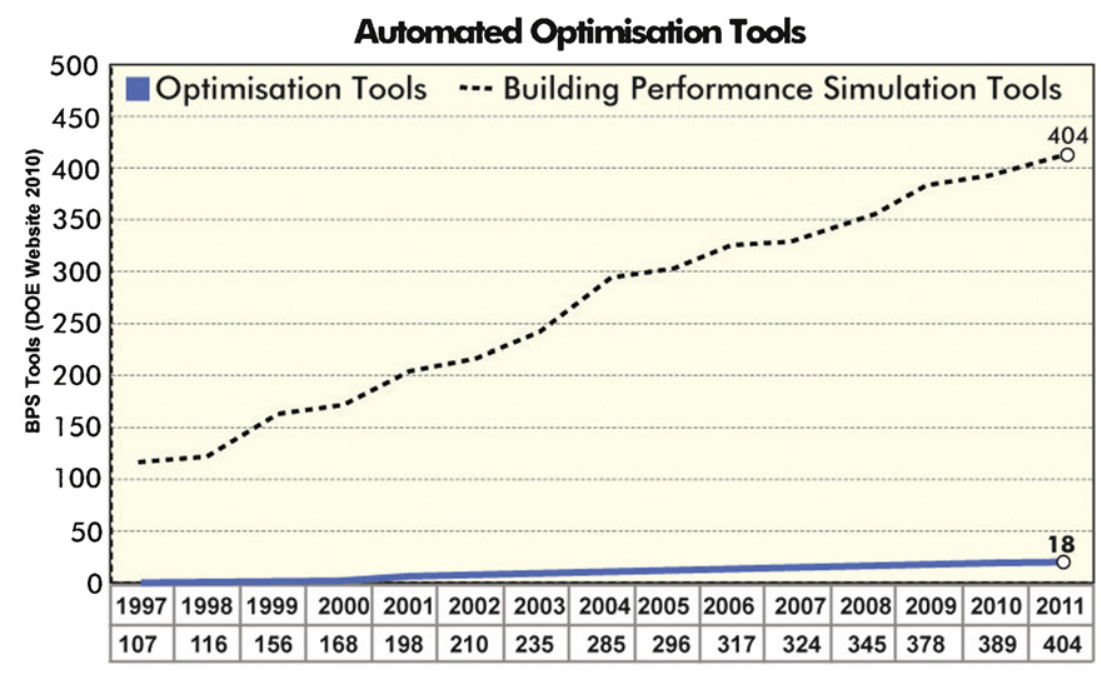

Fig. 1. The evolution of building performance simulation and optimization tools [33]. 
the cost function is smooth and coercive. Emmerich et al. [116,117] used the Hooke-Jeeve algorithm is used to minimize the energy consumption considering different building scenarios and characteristics. A gradient-free sequential quadratic programming (SQP) filter algorithm is proposed and test in Pedersen's PhD work [103]. The algorithm can converge fast and in a stable manner, as long as there are no active domain constraints.

Generally, the deterministic algorithms need that the evaluation functions have particular mathematical properties like the continuity and the derivability $[15,82]$. Therefore, they are not the best choice for handling discontinuous building and HVAC problems with highly constrained characteristics and multi-objective functions. On the other hand, the advantage of the stochastic algorithms is that they do not have much mathematical requirements for solving the optimization problem [118]. Examples of stochastic algorithms that are designed to deal with highly complex optimization problems are [119]: annealing [120-122], tabu search [123], ant colony [124], particle swarm [125] and genetic algorithms [126-128].

Stochastic element was added to pattern search algorithm for optimizing the topological design of the bracing system for a freeform building [129]. Ant colony optimization algorithm (ACO) was used to search for a trade-off between light intake, thermal performance, view, and cost for a panelled building envelope for a media centre in Paris [130]. A strength multi-objective particleswarm optimization (S-MOPSO) was used for the optimization of a heating, ventilation, and air conditioning (HVAC) system in an office building [131].

Instead of the above algorithms, the last 10 years has seen an increasing interest in using genetic algorithms (GAs) for optimization of building and HVAC systems. The GAs are the most efficient stochastic algorithms when the optimization problem is not smooth or when the cost function is noisy [132,133]. The GAs consider many points in the search space simultaneously, not a single point, thus they have a reduced chance of converging to local minimum, in which other algorithms may end up [107]. The GAs with the Pareto concept are used widely in energy and buildings studies $[7,16,40,41,47,48,92,94,102,110,134-136]$. According to the studies of Zitzler [137] and Deb [128], the elitist nondominated sorting genetic algorithm (NSGA-II) seems to be the most efficient GAs. The NSGA-II is implemented to find trade-off relations between energy consumption and investment cost or thermal comfort level of buildings [70-72,86,106,111,138,139]. The NSGA-II [128] could be one of the most suitable optimization algorithms to handle multi-objective multivariate building and HVAC design problems with discrete, non-linear, and highly constrained characteristics. However because its stochastic behaviour, it could occasionally fail to get close to the pareto-optimal front, particularly if low number of evaluations is implemented [86,87]. The high number of iterations is chosen to avoid the early breakdown of the optimization [106]. Since building simulation is often very time-consuming, a large number of iterations could not be practical. Deterministic optimization phases and archive strategies are added to the original NSGA-II in order to perform rapid optimization using a low number of simulation runs - and/or to guarantee optimal or close-to optimal solution set for building design problems $[17,87,98]$. The proposed algorithms/approaches (PR_GA, GA_RF, PR_GA_RF, and a NSGA-II) reduce the random behaviour of the original NSGA-II enhancing the repeatability of the optimization results.

\subsection{Tools of $B P O$}

As shown in Table 1, BPO tools can be classified into two main group's stand-alone optimization packages and simulation based optimization tools. The list of stand-alone optimization tools is not very long, however we chose to present the most frequently mentioned tools in literature namely GenOpt ${ }^{\circledR}, \mathrm{MATLAB}^{\circledR}$, modeFrontier $^{\circledR}$ and Topgui $^{\circledR}$. However, in the past 10 years, several advances have been made to develop building simulation tools that are driven by feedback from performance objectives. Largely these tools are directly towards industry to dramatically decrease the energy footprint of new buildings. Consider the most mentioned two tools in literature that attempt to merge both optimization and simulation techniques developed at national renewable energy laboratories (NREL): $\mathrm{BeOpt}^{\mathrm{TM}}$ and Opt-E-Plus ${ }^{\mathrm{TM}}$.

\subsubsection{GenOpt ${ }^{\circledR}$}

GenOpt ${ }^{\circledR}$ is stand-alone optimization software developed at Lawrence Berkeley National Laboratory (LBNL). GenOpt is a generic optimization programme that can be used with any simulation programme that has text-based input and output, such as EnergyPlus, DOE-2, IDA-ICE, SPARK, BLAST, TRNSYS, or any user-written code [140]. It is suitable to be coupled with any text-based simulation programme. This tool is able to access a library of different optimization algorithms, and can use either continuous or discrete variables. The modularity, flexibility, and ability to select from a range of optimization strategies make GenOpt a robust platform, but its visualization capabilities are limited. The tool is aimed to solve problems where the objective function is computationally expensive and its derivatives are not available or do not exist, thus it is not suitable for linear programming problems, quadratic programming problems and problems where the gradient of the objective function is available. The independent variables can be continuous, discrete or both. Constraints on dependent variables can be implemented using penalty or barrier functions. GenOpt ${ }^{\circledR}$ provides multidimensional and one-dimensional optimization algorithms. However, its library does not include multi-objective algorithms.

The algorithms for multidimensional optimization are: (i) generalized pattern search methods for continuous independent variables (the coordinate search algorithm and the Hooke-Jeeves algorithm), which can also be run using multiple starting points, (ii) discrete Armijo gradient for continuous independent variable, (iii) particle swarm optimization algorithms for continuous and/or discrete independent variables, which can be used in the versions with inertia weight or with constriction coefficient and with a modification that set the continuous independent variables on a fixed mesh in order to reduce computational time, (iv) hybrid generalized pattern search algorithm with particle swarm algorithms for continuous or/and discrete independent variables, and (v) simplex algorithm of Nelder and Mead for continuous independent variables $[141,142]$. On the other hand, the algorithms for one-dimensional optimization are: (vi) the golden section interval division and (vii) the Fibonacci division. GenOpt ${ }^{\circledR}$ automatically allows parallel computing if the computer has multiple CPUs, significantly reducing computational time [143]. The modularity, flexibility and wide availability of optimization techniques make GenOpt ${ }^{\circledR}$ a robust optimization environment, but its postprocessing capabilities are limited [47].

In the field of BPO, GenOpt has been used by several researchers including Coffey et al. [144,145], Congradac and Kulic [107], Corbin et al. [22], Djuric et al. [146,147], Jacob et al. [148], Hasan et al. [85], Kummert [149], Magnier et al. [150,151], Palonen et al. [86], Park et al. [152], Henze et al. [153], Stephan et al. [57], Wetter and Wright [15] and Wright and Farmani [91].

\subsubsection{MATLAB}

For less simulation efforts and feasible optimization results, it is essential to develop the link between existent building simulation tools and trusted optimization tools. In environmental design of buildings, since the number of design variables is usually large 
and the true nature of solution space (linear or non-linear) cannot be known, optimization tool has to provide access to different types of algorithms to suit problem needs. This aspect is provided into MATLAB which is trusted tool comprises a lot of optimization solvers able to deal with different types of optimization problem. Additionally, with this approach, the user can utilize all MATLAB functions which provide significant tools to attain and analysis the optimal results

MATLAB Optimization Toolbox ${ }^{\mathrm{TM}}$ provides a variety of algorithms for optimization problems. These algorithms solve constrained and unconstrained continuous and discrete problems. MATLAB includes functions for linear programming, quadratic programming, binary integer programming, nonlinear optimization, nonlinear least squares, systems of nonlinear equations, and multi-objective optimization. This allows finding optimal solutions, performing trade-off analyses, balancing multiple building design alternatives, and incorporating optimization methods into algorithms and models [34].

In the field of BPO, MATLAB has been used by several researchers including Bucking [9], Choudhary [105], Coffey et al. [144,145], Jacob et al. [148], Hasan et al. [85], Hamdy et al. [87], Henze et al. [153], Kummert [149], Park et al. [152], Shea et al. [130], Wetter [101], Wright and Farmani [91].

\subsection{3. modeFRONTIER}

modeFRONTIER is a multidisciplinary and multi-objective software that allows complex algorithms to spot the optimal results, even conflicting with each other or belonging to different fields. The tool be coupled to different other software packages in different input/output interchange formats including: EnergyPlus, ESP-r Fluent, and MATLAB. Once data have been obtained, the user can turn to the extensive post-processing features to analyze the results. The software offers wide-ranging toolbox, allowing the user to perform sophisticated statistical analysis and data visualization.

The tool has been used by Xing [154] find the best insulation strategy to minimize the space conditioning load of an office building while keeping the insulation usage at minimum. Also the tool has been used by the unit of building physics and systems, Eindhoven University of Technology in the Netherlands, including the work of Hoes et al. [138] and Loonen et al. [139].

\subsubsection{Topgui}

Topgui is a MATLAB ${ }^{\text {TM }}$ graphical user interface (GUI) programme originally developed to be coupled with finite element analysis models for executing topology optimization. In the current version, it provides several single-objective and multi-objective optimization techniques: Hooke-Jeeves algorithm, generalized pattern search methods, particle swarm optimization algorithms, evolutionary strategy, non-dominated sorting genetic algorithm II (NSGA-II), s-metric selection evolutionary multi-objective optimization algorithm (SMS-EMOA).

In the field of BPO and according to the literature review, Topgui has been used mainly by Hopfe [106] and Emmerich et al. [116,117] aiming to evaluate optimization methodologies for future integration in BPS tools.

\subsubsection{Opt-E-Plus ${ }^{\mathrm{TM}}$}

Opt-E-Plus is a tool developed by NREL that uses EnergyPlus simulation engine. Opt-E-Plus utilizes various search routines to identify optimal buildings designs for energy usage [155]. The framework consists of a collection of EnergyPlus input and output files, system directories, and computer routines that use an XML data model to transfer information among the various components. The user is able to modify parameters in a .xml file, rather than directly modifying the EnergyPlus input files. This application integrates with multiple data sources, is modular to allow distributed programming, and supports selection of automation and optimization strategies. Although this is not a stand-alone optimization tool, it is developed to guide the user, through the comparison of various design options, towards the most economical energy savings. The structure of the programme is modular to allow distributed programming [155]. Visualization of the trade space however is limited, and it does not support multidisciplinary optimization. Also the programme is restricted to North American context. OptE-Plus has been used by NREL researchers and others including the work of Herrmann et al. [156] and Long et al. [157].

\subsubsection{BEopt ${ }^{\mathrm{TM}}$}

BEopt $^{\mathrm{TM}}$ is a tool developed by NREL and is designed to identify optimal building design variants on the path to net zero energy target. The software allows the user to select discrete options for various building variables regarding building envelope and HVAC systems and calculates energy savings with respect to a user-defined reference case or a climate-specific Building America Benchmark $[158,159]$. Regarding energy simulation, BEopt ${ }^{\mathrm{TM}}$ can use as simulation engine either DOE-2 [160] or TRNSYS [161] and the optimization is executed by a sequential search technique in order to find the most cost effective combination of energy efficient measures and photovoltaic systems [8]. The software rapidly provides the user a design space (or problem space); however the proposed design space and the selectable objective functions are limited. Also the programme is restricted to North American context.

Construction variables such as window and wall types were used as inputs for a DOE-2.1 energy model and TRNSYS was used to implement solar modules. More recently, the energy model has been update to use EnergyPlus for both building and solar component simulations. An objective of BEopt's approach is not to focus on one final optimal solution, but on pathways to optimal designs such that the user can select designs which best suit their financing available for the housing project. Integration with SketchUp, a computer aided design tools, greatly simplify the creation of building models used for building simulation. Opt-E-Plus is a commercial building optimization tool which uses sequential searches and EnergyPlus for building simulations. Opt-E-Plus also integrates with SketchUp to create building models used for optimization studies. The application includes a graphical user interface (GUI) that allows the user to select from a range of predefined and discrete building alternatives to be used in the optimization process. BEopt allows the user to rapidly generate and visualize the design space through a browser, but its flexibility is limited as a result of having predefined building alternatives and its inability to consider a wide range of objective functions.

BEopt has been used by NREL researchers and others including the work of Anderson et al. [162], Givler [163] and Polly et al. [164].

\section{Interview results and analysis}

The previous section was a literature review that defined BPO and illustrated its history, methods, characteristic and tools to support it. This section presents some of the interview results that interviewed optimization experts in 2011. Each interview included 25 questions available in the final study report [165]. For this paper, representative questions that reflect the most important findings are selected. The complete results are presented and can be found in the final study report [165]. Prior to analysing the interview results, it is important to question the statistical significance of the interview sample. In fact, 28 participants were interviewed from a list of 40 potential users. The list was developed by the IEA task 40 members and the interviewed experts themselves. Thus the interview sample is highly representative of researchers. 

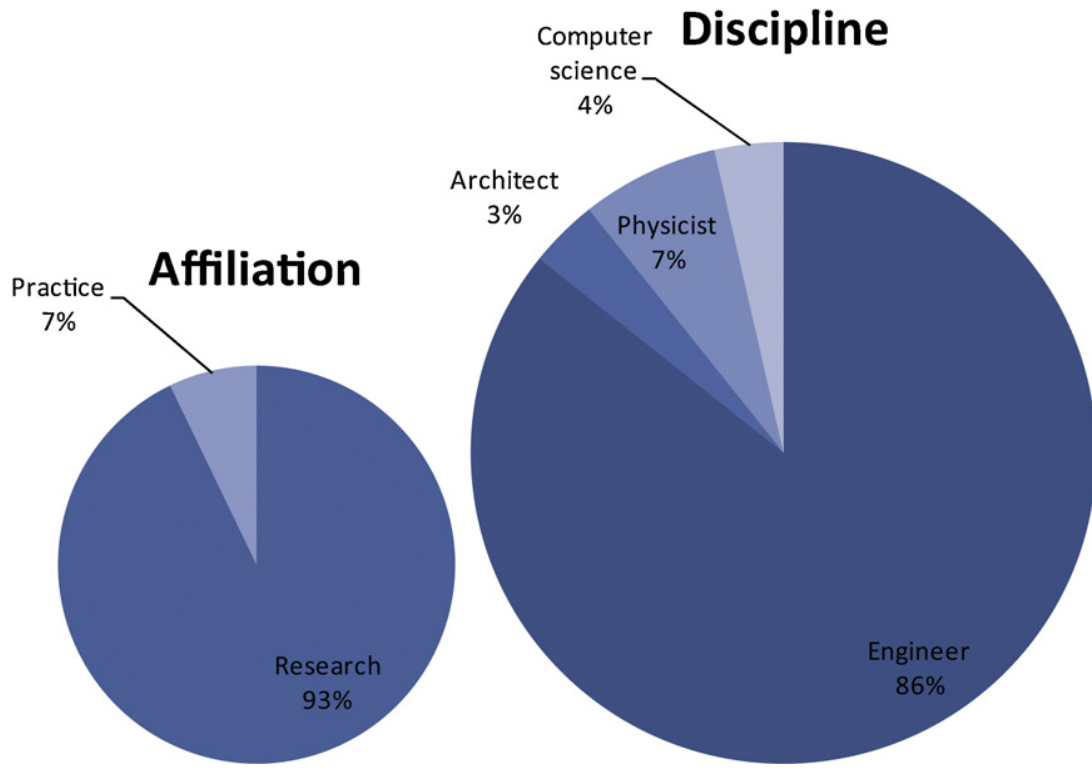

Fig. 2. Field of discipline of interviewed experts.

\subsection{Interviewee's background}

What is your major field of discipline (architecture, engineering, computer science other)?

28 experts were interviewed where 26 had their background in engineering, 2 had their background in physics, one in architecture and one in computer science (Fig. 2). Among the 28 experts 26 identified themselves as researchers and 2 identified themselves as practitioners (Fig. 2). The affiliation of the interviewed experts shows that they are mostly located in universities or research labs in the Northern Hemisphere. The majority of interviewees work in the United States (29\%), the UK (18\%), Canada (14\%), Finland (10\%), the Netherlands (7\%), Germany (3\%), Switzerland (3\%) and Japan (3\%).

How many projects or case studies have you performed and how long does each project or case study take?

In average $40 \%$ of all interviewees (11) conducted between 5 and 10 optimization cases or projects, 32\% (9) conducted less than 5 cases or projects and $11 \%$ (3) conducted between 10 and 15 optimisations while only $14 \%$ (4) conducted more than 15 optimisations. Most interviewees mentioned that they start with the model development and calibration followed by linking the simulation tool to the optimization tool, and then run the optimization. Fig. 3 shows the time for each case or projects. Interviewees mentioned that the development and calibration of the simulation models are one of the time consuming steps, requiring in average 2-3 weeks of work. However, the running time of the optimization simulations is the most time consuming process and depending on the model resolutions the time required for every case varies significantly.

What kind of tools do you use for optimization (MATLAB, GENOPT, others)? To which simulation tool do you couple it?

Fig. 4 reveals that MATLAB toolbox and GenOpt are the most used optimisations tools. The left figure indicates that the most used simulation tools among interviewees is (9) EnegryPlus and (7) IDA ICE followed by (5) TRNSYS and (3) Esp-r.

\subsection{Optimization methodology}

Which building typologies have you used optimization for and in which climates? (Residential, offices, retail, institutional)

Fig. 5 shows the building typologies, construction types and climate were the projects were optimized.
How many zones do you address in your model when running optimisations? And what kind of design variables do you set for optimization?

$64 \%$ of the interviewees used multi-zone model while $36 \%$ used single zones models. Interviewees indicated that the preference of choice between the single and multi-zone modelling depends on the model resolution (level of detail) and the expected interactions between the each thermal zone and the systems. Also the multi-zone model was used to differentiate between heated and non-heated zones and between frequently and less frequently used spaces of the building.

As shown in Fig. 6, the most optimized design variables by the interviewed experts for NZEBs were systems and controls (53\%) followed by the envelope (50\%). The optimization of control systems and in particular model predictive control was considered as one of the most complex and dynamic design variables therefore, design optimization was necessary. Renewable systems were optimized by $50 \%$ of the interviewees. Thermal storage, layout and

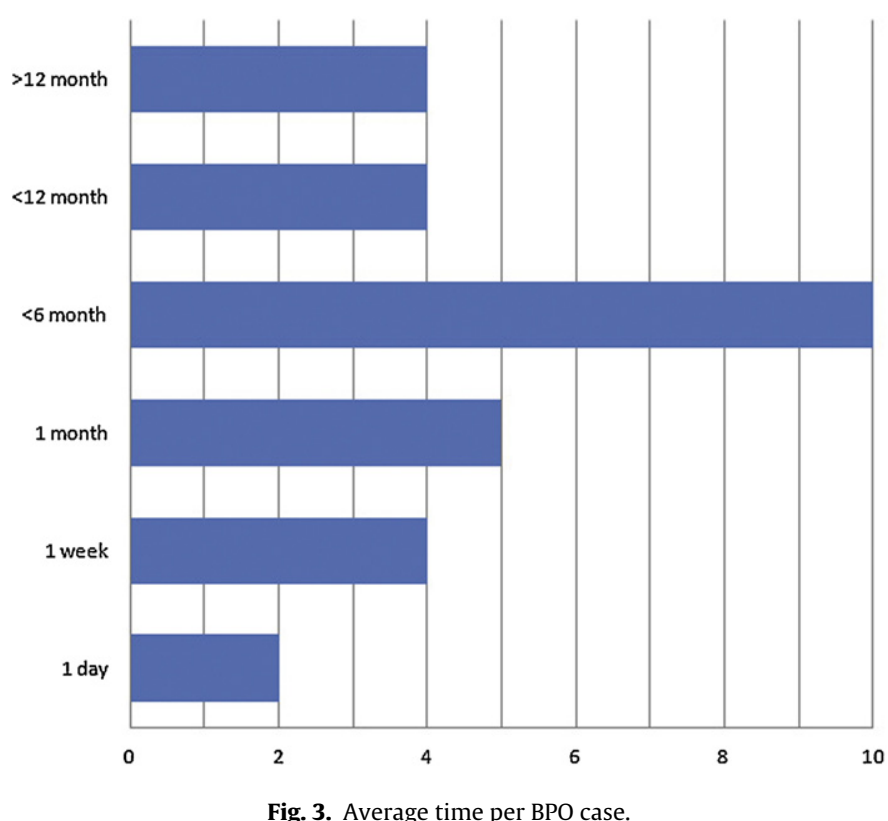

Fig. 3. Average time per BPO case. 


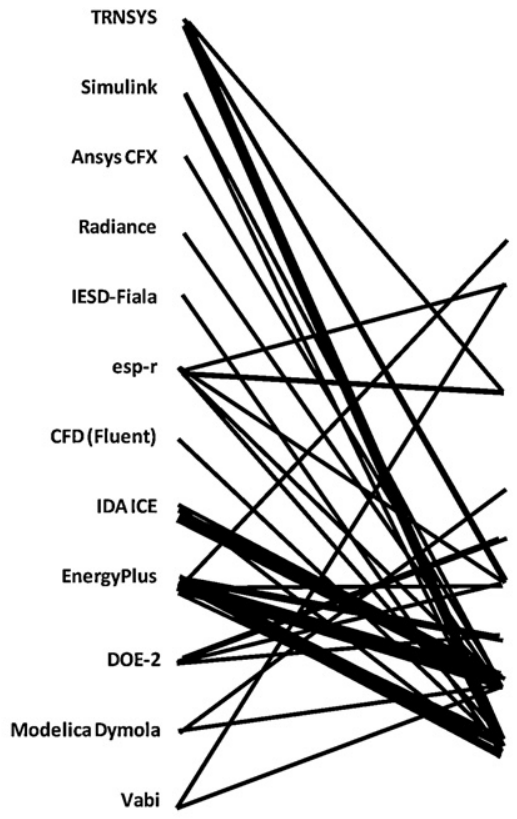

Simulation Tools

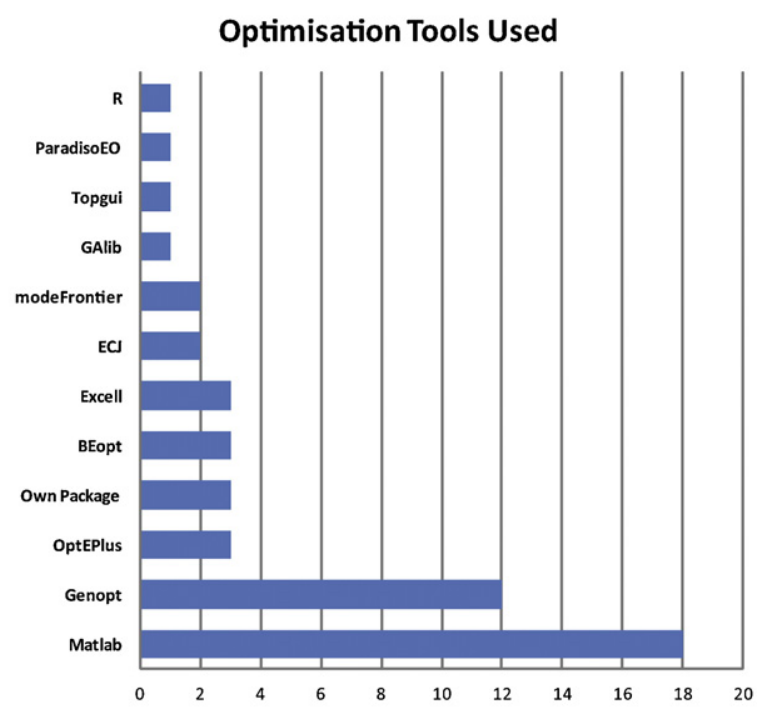

Optimisation Tools

Fig. 4. Optimization tools order by use (right) and simulation tools ordered by use (left). The line thickness is proportional to the frequency of the pairings.

geometry was optimized by $25 \%$ of the interviewees followed by internal gains (18\%). $11 \%$ of the experts optimized occupancy and $7 \%$ optimized location and climate. The analysis of Fig. 6 shows that the most optimized design variables where late design parameters. According to the interviewees the choice of the design variable was based on the innovation of the design project and the complexity of a particular design variable.

What kind of objectives do you set for optimization?

Common optimization criteria in building design are various costs such as initial capital cost and annual operating cost, and life cycle cost, energy consumption and recently environmental impact. $70 \%$ of all interviewees do multi-objective optimization versus $30 \%$ who do single objective optimisations. Regarding the objectives, all interviewees (28) chose energy as the most used optimization objective, while 64\% (18) chose cost.

The cost objectives included the life cycle cost, initial cost, operation and maintenance cost. Comfort followed (10) as the third most important objective while some interviewees indicated that they consider comfort as a constraint so I wouldn't call it an objective. As shown in Fig. 7 carbon (5), lighting (2) and indoor air quality (1) were ranked at the end.

What kind of constraints do you set for optimization?

As shown in Fig. 8, there was agreement among most interviewees (22) to set thermal comfort as the main constraint followed by cost (18). Interviewees refer to comfort conditions defined by standards. There was an agreement to consider constrains as

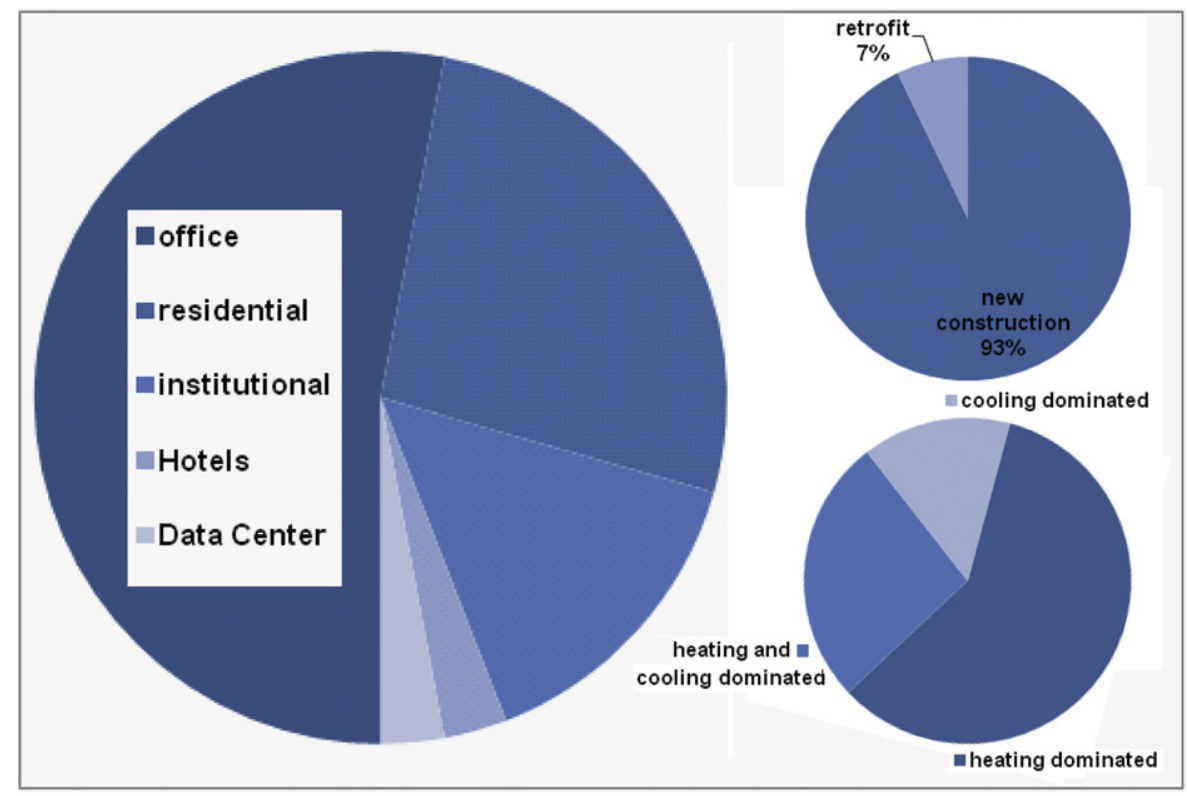

Fig. 5. Building typologies, construction type and climate. 


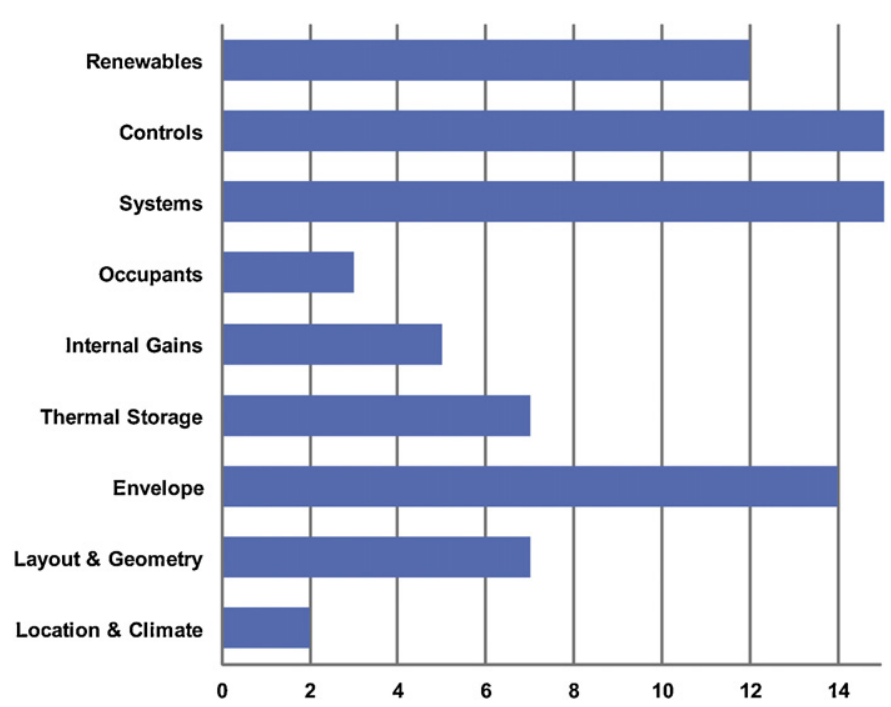

Fig. 6. Participants' choices of optimization design variables.

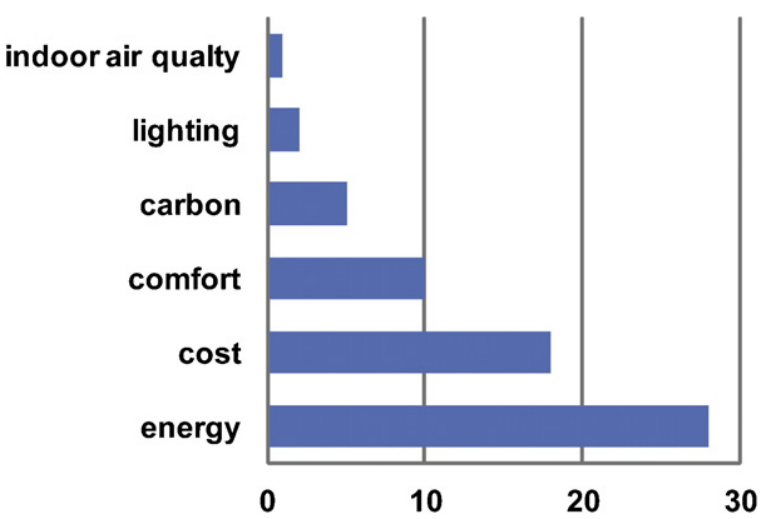

Fig. 7. Participants' choices of optimization objective functions.

primarily to define the feasible domain. Also penalty terms are used in the optimization work to both guide the optimizer away from infeasible regions and also to consider the impact of thermal comfort boundaries on the optimization. Constraints in this case were boundary or equation based.

Under which setting you run you optimization what is your methodology? What kind of stopping criteria do you set for optimization?

The answer to this question depended on the used algorithm. Interviewees indicated that some algorithms have stopping criteria built in, others run for a prescribed number of generations or

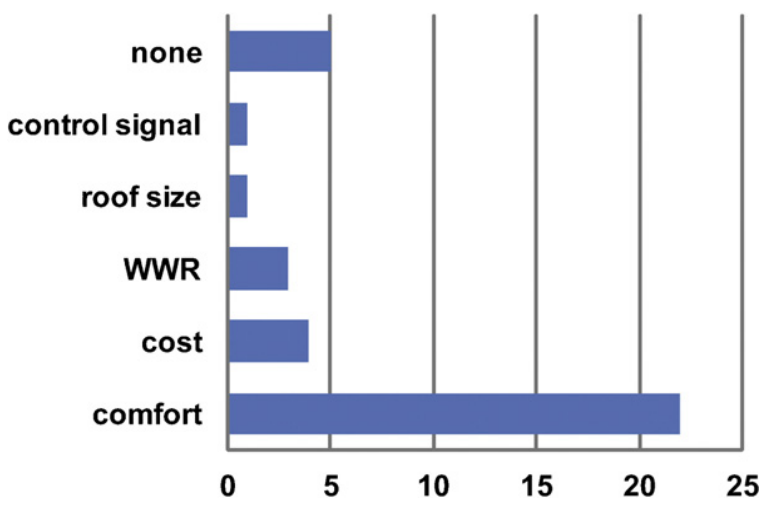

Fig. 8. Participants' choices of optimization constraints.

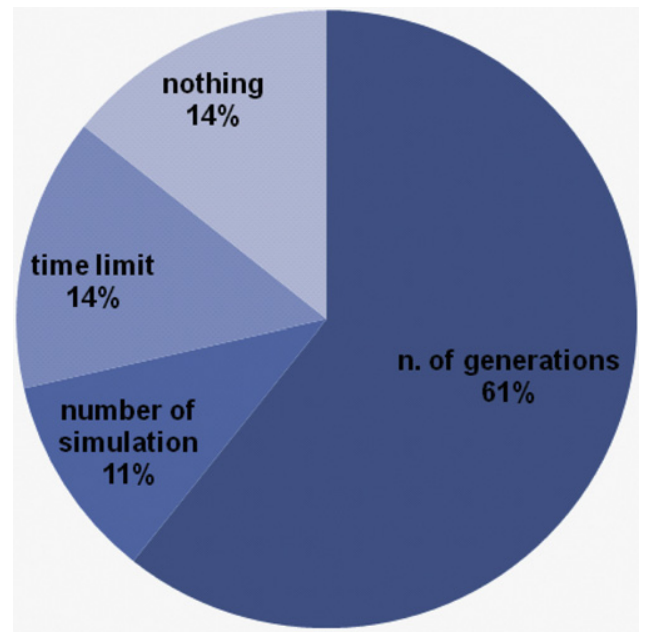

Fig. 9. Participants' choices of optimization stopping criteria.

simulations. However, as shown in Fig. 9 most interviewees (17) set a number of generations as stopping criteria for their optimization work. Some set a time limit (4), or no stopping criteria at all (4) while few (3) set a number of simulations.

\subsection{Output}

Do you have GUI for your own optimization tool? And which kind of output analysis visualization did you do using optimization tools $(1-14) ?$

$75 \%$ of interviewees indicated that they do not have an environment or package with a GUI for output post processing and analysis visualization. Most interviewees are forced to process and convert the output data using different processing tools, such as DView, Excell, gnuplot or writing scripts in MATLAB, in order to create interpretable output results.

Fig. 10 illustrates the 14 most used output analysis graphs. 22 of the interviewees use the graph Fig. 10.5 allowing plotting the solution space using the Pareto Front. Interviewees indicated that the Pareto Front include many solution that they can pick from a variety of solutions. This was followed by Fig. 10.8 (15 interviewees) that allows the visualization of energy, cost or carbon emissions of different solution cases representing the basecase versus the optimized case. Also Fig. 10.4 and 10.6 was selected by 12 interviewees to visualize the impact of any parameter variation. In general, every respondent had his or her own custom visualization techniques, for example line plots (Fig. 10.2) or time series (Fig. 10.7) are used for controls and in the case of comfort scatter plots (Fig. 10.2) are used.

\subsection{Integration of optimization with design process}

This part of the interview was structured around a series of open questions in order to get more insights on the integration of optimization techniques in the design process. A selection of the comments and their frequency is classified as follows:

What opportunities you see in integrating optimization techniques in NZEB design process?

According to the interviewees BPO have been applied successfully in numerous NZEB projects. However the building simulation community still rarely uses optimization and little investment has been made to advance BPO. However, interviewees indicated that many opportunities in integrating simulation based BPO in NZEB design and operation. The most mentioned opportunities include:

- Support the decision making for NZEB design. The rise of simulation has been driven by many things, including government policy 


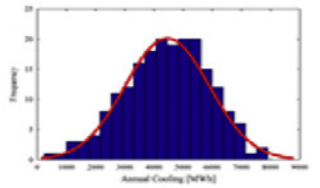

1. Column (frequency)

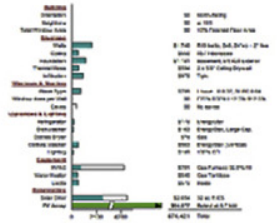

6. Bar

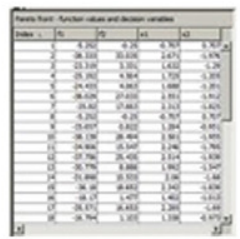

11. Table

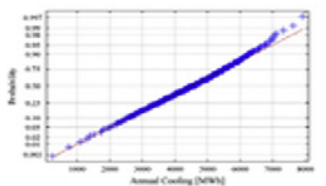

2. Scatter (probability)

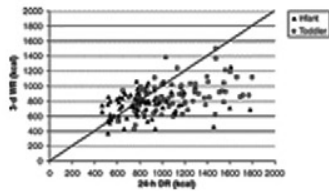

7. Time series

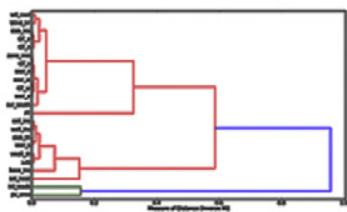

12. Dendrogram
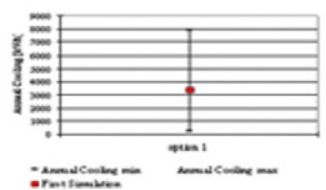

3. Stock (range)

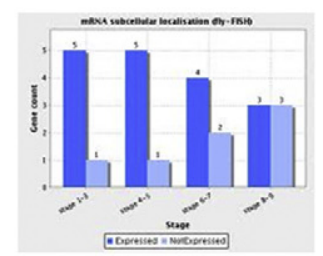

8. Bar Chart

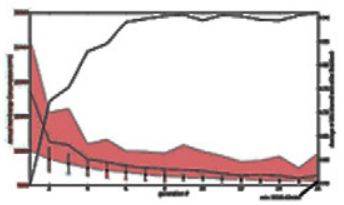

13. Convergence Diagram

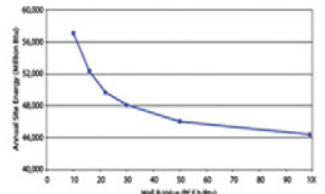

4. Line

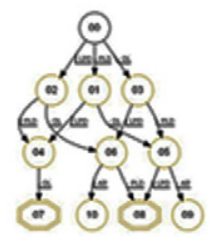

9. Tree Diagram

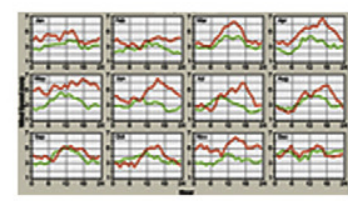

14. Multiple Line

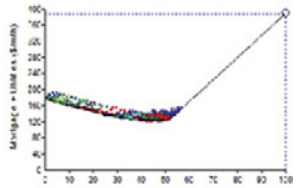

5. Scatter

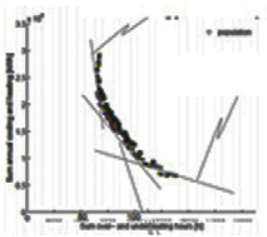

10. Linear trade Off

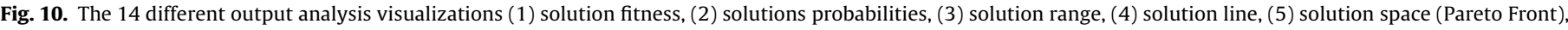

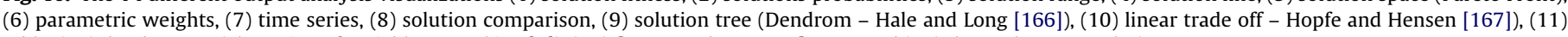
table, (12) dendrogram (clustering of variables - Bucking [9]), (13) fitness and average fitness, and (14) thermal contour plot).

that pushes the design of low energy buildings. At present, any increase in the use of optimization will be driven by the extent to which aids design decision making. In this respect, one of the most powerful forms is multi-object optimization, since it gives a set of solutions that lie on the trade-off between two or more conflicting design objectives. The trade-off can be used to explore the impact of say of less capital investment on the increase in carbon emissions. This kind of information being useful in decision making of NZEB requiring little effort and generates different ideas and alternatives.

- Designing innovative integrated NZEBs and thermal (and visual) comfort control systems are difficult to design because they involve complex systems that interact dynamically. Optimization algorithm can help in finding the optimal and near optimal solutions regarding the design and sizing of passive and active energy systems and finding the balance between demand and production.

- Achieving cost-effective NZEBs by analyzing and synthesizing multi-physics systems that may include passive and active facades, lighting controls, natural ventilation, HVAC, and storage of heat in the building structure combining advanced technologies such as micro-CHP, PV, PVT, solar collectors and micro-wind). The complexity of such systems pose a serious challenge to designers and using BPO is an opportunity for optimal and costeffective design decision during building design and operation including the existing building stock.

- Allow optimal systems scheduling through model predictive control (MPC) taking into account the dynamics of NZEB systems and anticipated future energy load. When solving the optimal control problem using MPC algorithm, it determine near-optimal control settings during design and operation and improve the NZEB load matching problem.

How can it be integrated into the decision making? How should optimization become more practically applied during early design phases?

There was an agreement among interviewees that prior to any integration effort there must be first commercial tools available with integrated simulation and optimization that allow seamless link between the simulation model and the optimization process. Currently, the time and knowledge required implementing separate simulation models and optimization algorithms is limiting the use of BPO in practice. However, on the long term the integration of BPO can be achieved through:

- Requiring optimization as a standard activity during NZEBs design and operation. BPO can be integrated and become standard in practice. Consequently BPS tool will integrate optimization techniques and the number of users will increase dramatically. In the coming year, I expect it to be a standard feature in NZEBs.

- Planning optimization early in the design process. BPO should be introduced in early phases of design as part of the integrated design process (IDP). The use of optimization should be during schematic design stages. Models should be simple with some geometrical zoning simplification. Using a standard reference building and testing all kind of technologies can help in establishing initial design concepts and solutions which can have an impact on all stakeholders. Showing results from the starting point can have a strong impact on cost, energy and thermal comfort and will allow a range of ideas and solutions.

- Informing all building stakeholders on the importance of optimization. Comparison studies on buildings with optimization and buildings without optimization will inform designers and clients. The optimization community should show designers that the use of optimization tools produce better results. By providing demonstration projects and real physical buildings beside the optimization models for simulation users. This will raise the confidence in the optimization and lead to more detailed and accurate and certain optimization models with operation patters and hours. Education in academia and practice has a key in guiding professionals how to perform optimization. 


\subsection{Optimization shortcomings}

What are the major practice obstacles of integrating optimization techniques in NZEB design?

The major obstacles of integrating optimization techniques in NZEB design can be classified under two main categories: (1) soft obstacles and (2) hard obstacles. The main four soft obstacles and their frequency is listed as follows:

- Low return and the lack of appreciation among the AEC industry (19)

- Lack of standard systematic approach to perform optimization in most cases researcher follow many different methods and ad-hoc approaches without a structure and categorisation in use (16)

- Requirement of high expertise (11)

- Low trust in the results (5)

Interviewees' indicated that in practice, there is a lack of awareness and confidence on the use of optimization. Also it is very important that users understand the optimization process. There is a large educational need before BPO gets applied routinely in the design process.

Regarding the hard or technical obstacles, the interviewees' comments and their frequency is listed as follows:

- Uncertainty of simulation model input (27)

- Long computation time (24)

- Missing information on cost, occupancy schedules, etc. (19)

- Difficulty of problem definition (objectives arrangement and constraint violation) (12)

- Missing environments integrating and linking simulation and optimization seamlessly (16)

- Low interoperability and flexibility of models for exchange between different design, construction, simulation, cost estimation and optimization tools (11)

- Lack of environment with friendly GUI allowing post processing and visualization techniques (7)

Interviewees' agreed that computation time is very long and this might well inhibit the initial take-up of optimization in practice. The optimization processes also magnifies the idea of "rubbish-inrubbish-out" since rather than simulate a single design solution, the errors or inaccuracies in a simulation are exposed across a wide range of the design space. This may lead to a need for better education and improved user interfaces for simulation, as well as more work on the uncertainty associated with simulation models.

Which tools would you recommend?

10 interviewees recommended GenOpt, 6 MATLAB, 4 BeOpt, 2 modeFrontier and 1 Topgui.

What features would you like to find in future tools?

Interviewees mentioned many ideas that contrast the hard obstacles mentioned previously. However, some significant ideas on future feature of optimization tools include:

- Doing optimization in real time within a BIM model and allowing adjustment on the fly

- Allowing parallel computing to reduce computation time

- Develop better GUI and model the building in 3D

- Couple simulation and optimization

- Connect real physical building components performance to optimization models for better information on cost and occupancy etc.

- Allow automation of building simulation with some default templates and strategies

- Profit from the gaming industry by developing interactive optimization environments for example talking to an oracle friend or wizard that guides the optimization process for better input quality and error detection and diagnostics

\section{Discussion}

From the interview results three themes were identified: the optimization context, the locus of optimization, and the factors that inhibit the uptake of BPO as decision support in the design of NZEBs.

\subsection{Summary of main findings}

For most interviewed experts evolutionary algorithms were found as a breakthrough that can help solving highly constrained envelope, HVAC and renewable optimization problems, while conventional algorithms just could not do it. Simple genetic algorithm solved many design, operation and control problems with relative ease. Evolutionary algorithms are adaptable and very powerful in finding good solutions. It is difficult to know whether they have found global minima, but this is not a critical flaw so long as they can measure the improvement in the optimality of a solution against a base case. It is also argued that the notion of trying to find an optimum is nonsense because there is so much uncertainty in the modelling that makes the simulation relates to reality. It is also the case that optimization is not so much about finding the "best" solution, but as much about exploring the design space for alternative solutions. Evolutionary algorithms are robust in exploring the search space for a wide range of building optimization problems. Unlike many other conventional or heuristic algorithms, Evolutionary Algorithms are also easily adapted to enable them to solve a particular optimization problem more effectively. Moreover, the rise of simulation has been driven by many things, including government policy that pushes the design of NZEBs. At present, any increase in the use of optimization will be driven by the extent to which aids design decision making. In this respect, one of the most powerful forms optimization is multi-object optimization, since this provides a set of solutions that lie on the trade-off between two or conflicting design objectives. The trade-off can be used to explore the impact of say of less capital investment on the increase in carbon emissions (this kind of information being useful in decision making). However, decision support, time, knowledge, lack of tools, and uncertainty were the themes that ran through the experiences of the interviewed experts. The factors that inhibit the uptake of BPO are not only related to the optimization techniques or the tools themselves, but also to the simulation models inputs, causing significant restrain in the AEC industry take-up. Interviewees' opinions about BPO, and their subsequent experiences, were found to be mostly influenced by their research work and community. From the evidence available, the optimization process did not, in general, seem to be systematic and design centred, apart from a small group of experts who used BPO in real design practice.

\subsection{Strengths and limitations of the study}

The methodology used in this study literature review and structured interviews was appropriate to generate hypotheses from a large population sample. Verbatim transcriptions were undertaken and selected quotations were not edited (Attia, 2012). There was independent analysis of the data and concordance in the identification of themes. The choice of setting, IBPSA and IEA, allowed experts to be recruited from practices who represent a range of NZEB and simulation groups. Furthermore, the experts formed a representative sample in terms of the outcomes related to BPO. The experts were made aware at the beginning of the interviews that the interviewer was a researcher, architectural engineer and IEA SHC Task 40/ECBCS Annex 52 members. While this knowledge may have been helpful in allowing experts to feel comfortable in 
an AEC setting, thereby facilitating discussions about building performance related matters, this knowledge may have had an impact on the data. Specifically, the experts may have felt obliged to align their views with what they perceived to be the established IBPSA standpoint, for instance offering a more positive opinion on BPO than they would have done otherwise.

The number of the expert group means that statistical representation cannot be claimed. Furthermore, it was not possible to ensure that the expert represented a desired broad range of optimization groups. The sampling strategy was therefore prospective rather than purposive, and it would have been preferable to interview more experts who declined the test and experts who do not speak English, as all of the interviewed were English speakers. Finally, it would have been preferable to interview more experts who work in practice.

\subsection{Implications for practice and future research}

The finding that BPO is surrounded by issues of uncertainty imposes new obligations on researchers and software developers. This involves embracing more design-centred optimization work in addition to setting systematic frameworks of performing optimization for design decision support, uncertainty and communication, and optimization-based building solutions. Moreover, reliable and accurate information on building performance is crucial for experts to create robust informed design choices. Optimization performed for designers needs to explain the impacts on the design quality both before and after the use of optimization, and the associated uncertainties need to be discussed.

Furthermore, recognition is needed that optimization is necessary for complex NZEBs. Designers do not rely on optimization sufficiently due to the lack of public domain design packages integrated with open domain, object oriented analysis tools. They are also influenced, often strongly, by the design complexity, limited time and investment pressure. Policymakers must therefore respond accordingly and recognize that BPO does not start and finish in the research labs. BPO could be required as a standard activity during NZEBs design and operation and made available in a range of public NZEB design practice. The greatest possibilities, however, are afforded by the researchers. Notwithstanding the real issue of computation time and the seamless integration of simulation and optimization model with design models. Ultimately in the future, all designers participating in the design (architects, engineers, etc.) will be involved in using BPO techniques. Optimization is about presenting design alternatives to the designer regardless of whom they are. So it might be that the architect has a different set of tools and it is a different optimization methodology but they will not be excluded from using optimization.

At present, the integration of BPO into the design process is a research issue. While this sample of experts confirms that BPO will add value to the design we do not have the proof. If we have solid proof designers will be very likely use optimization techniques because it enhances the buildings they are designing, so they can get better buildings. More research is needed on the experience of designers with BPO. Research has to show designers that the use of BPO produce results better than their design. This would also allow the development of better BPO tools that are both accurate and support the decision making.

\section{Acknowledgements}

The authors express their thanks to Scott Bucking, Remi Charon, Ruchi Choudhary, Brian Coffey, Chad Corbin, Natasa Djuric, Elaine Hale, Mohamed Hamdy, Ala Hassan, Jan Hensen, Gregor Henze, Lesley Hermann, Pieter-Jan Hoes, Christina Hopfe, Dirk Jacob, Michael
Kummert, Nicholas Long, Laurent Magnier, Peter T. May-Ostendorp, Monjur Mourshed, Tatsuo Nagai, Matti Palonen, Christian Struck, Mika Vuolle, Weimin Wang, Michael Wetter, Jonathan Wright and Yi Zhang and appreciate their valuable comments and feedback. The authors thank Josef Ayoub, Natural Resources Canada, Andreas Athienitis, Concordia University and IEA SHC Task40/ECBCS Annex 52, Subtask B for comments on earlier versions of this article.

\section{References}

[1] IEA. TASK 40/Annex 52 (2008). Towards net zero energy solar buildings, IEA SHC Task 40 and ECBCS Annex 52. http://www.ieashc.org/task40/index.html, 2011 (accessed 10.01.2011).

[2] European Parliament Report on the proposal for a directive of the European Parliament and of the Council on the energy performance of buildings (recast) (COM(2008)0780-C6-0413/2008-2008/0223(COD)), 2009.

[3] ASHRAE. AHSRAE Vision 2020, ASHRAE Vision 2020 Ad Hoc Committee. http://www.ashrae.org/doclib/20080226 ashraevision2020.pdf, 2008 (accessed 10.10.10).

[4] A. Athienitis, et al., Strategic design, optimisation, and modelling issues of netzero energy solar buildings, in: Proceeding of EuroSun 2010, Graz, Austria, 2010.

[5] S. Hayter, P. Torcellini, R.B. Hayter, R. Judkoff, The Energy Design Process for Designing and Constructing High-Performance Buildings, in: Clima 2000/Napoli 2001 World Congress, 2001.

[6] M. Wetter, GenOpt ${ }^{\circledR}$, generic optimisation program, in: Building Simulation 2001 Conference, Rio de Janeiro, Brazil, 2001.

[7] R. Charron, A. Athienitis, The use of genetic algorithms for a net-zero energy solar home design optimisation tool, in: Proceedings of PLEA 2006 (Conference on Passive and Low Energy Architecture), Geneva, Switzerland, 2006.

[8] C. Christensen, R. Anderson, et al. BEopt software for building energy optimisation: features and capabilities. National Renewable Energy Laboratory (NREL) Technical Report NREL, TP-550-39929, 2006.

[9] S. Bucking, Design optimisation methodology for a near net zero energy demonstration home, in: Proceeding of EuroSun 2010, Graz, Astria, 2010.

[10] C. Brown, L. Glicksman, M. Lehar, Toward zero energy buildings: optimized for energy use and cost, in: SIMBuild fourth National Conference of IBPSA-USA, 11-13 August 2010, New York City, NY, 2010.

[11] IBPSA. The International Building Performance Simulation Association. http://www.ibpsa.org/, 2011 (accessed 01.10.2011).

[12] P. Torcellini, S. Pless, M. Deru, D. Crawley, Zero energy buildings: a critical look at the definition, in: ACEEE Summer Study, Pacific Grove, CA, 2006.

[13] J. Snyman, Practical Mathematical Optimisation-An Introduction to Basic Optimisation Theory and Classical and New Gradient-Based Algorithms, Springer Science + Business Media, University of Pretoria, Pretoria, South Africa, 2005.

[14] A. Carlos, et al., Applications of Multi-Objective Evolutionary Algorithms, World Scientific, Singapore, 2004, ISBN 981-256-106-4.

[15] M. Wetter, J. Wright, A comparison of deterministic and probabilistic optimisation algorithms for nonsmooth simulation-based optimisation, Building and Environment 39 (2004) 989-999.

[16] W. Wang, R. Zmeireanu, H. Rivard, Applying multi-objective genetic algorithms in green building design optimisation, Building and Environment 40 (11) (2005) 1512-1525

[17] M. Hamdy, A. Hasan, K. Siren, Applying a multi-objective optimisation approach for design of low-emission cost-effective dwellings, Building and Environment 46 (2011) (2011) 109-123.

[18] M. Wetter, GenOpt, Generic Optimisation Program, Release 3.1.0, Lawrence Berkeley National Laboratory, University of California, United States, 2011, http://simulationresearch.lbl.gov/GO/ (accessed 22.01.2012).

[19] modeFontier. ESTEC, multi-objective optimisation and design environment http://www.modefrontier.com/homeMF.html, 2012 (accessed 22.01.2012).

[20] Phoenix Integration. PHX ModelCenter, Graphical environment for automation, integration, and design optimisation. http://www.phoenix-int.com/index.php, 2012 (accessed 22.01.2012).

[21] P. May-Ostendorp, G.P. Henze, C.D. Corbin, B. Rajagopalan, C. Felsmann, Model-predictive control of mixed-mode buildings with rule extraction, Building and Environment 46 (2) (2011) 428-437.

[22] C. Corbin, G. Henze, P. May-Ostendorp, A model predictive control optimisation environment for real-time commercial building application, Journal of Building Performance Simulation 6 (2011) 2011.

[23] J. Candanedo, A. Athienitis, Predictive control of radiant floor heating and transmitted irradiance in a room with high solar gains, ASHRAE Transactions 117 (2) (2011) 235-256.

[24] J. Hensen, Lamberts R, Building Performance Simulation for Design and Operation, 1st ed., Spon Press, Oxfordshire, UK, 2011, ISBN-10: 0415474140.

[25] C. Christensen, et al., BEoptTM: software for identifying optimal building designs on the path to zero net energy, in: Proceedings of ISES 2005 Solar World Congress, Orlando, FL, USA, 2005.

[26] BPIE. Cost optimality discussing methodology and challenges with the recast energy performance of building directive. The buildings performance 
institute Europe - BPIE, 2010. http://www.bpie.eu/cost_optimality.html, 2010 (accessed 1.06.2011).

[27] G. Augenbroe, Integrated building performance evaluation in the early design stages, Building and Environment 27 (2) (1992) 149-161.

[28] J. Hensen, Towards more effective use of building performance simulation in design, in: Proc. 7th International Conference on Design \& Decision Support Systems in Architecture and Urban Planning, 2-5 July, Technische Universiteit Eindhoven, 2004.

[29] D. Crawley, et al., Contrasting the capabilities of building energy performance simulation programs, Building and Environment 43 (4) (2008) 661-673.

[30] S. Attia, A. De Herde, Early Design Simulation Tools for Net Zero Energy Buildings: A Comparison of Ten Tools, International Building Performance Simulation Association, Sydney, Australia, 2011.

[31] DOE, U.S. Building energy software tools directory. http://apps1.eere. energy.gov/buildings/tools_directory/, 2012 (accessed 1.06.2012).

[32] M. Wall, GAlib: A C++ Class Library of Genetic Algorithm Components, Technical Report, Department of Mechanical Engineering, Massachusetts Institute of Technology, Cambridge, MA, USA, 1996.

[33] S. Attia, et al., Selection criteria for building performance simulation tools: contrasting architects' and engineers' needs', Journal of Building Performance Simulation 5 (3) (2011) 155-169.

[34] MATLAB, MathWorks, Programming Environment for Algorithm Development, Data Analysis, Visualization, and Numerical Computation, Version 6.2, The MathWorks, Inc., Natick, MA, 2012, http://www.mathworks.com/ products/matlab/ (accessed 22.01.2012).

[35] Y. Zhang, 'Parallel' EnergyPlus and the development of a parametric analysis tool, in: IBPSA BS2009, 27-30 July, Glasgow, 2009, pp. 1382-1388.

[36] C. Coello, Evolutionary multiobjective optimisation: a historical view of the field, IEEE Computational Intelligence Magazine 1 (1) (2006) 28-36.

[37] J. Jo, J. Gero, Space layout planning using an evolutionary approach, Artificial Intelligence in Engineering 12 (3) (1998) 149-162, ISSN 0954-1810, 10.1016/S0954-1810(97)00037-X.

[38] J. Gero, V. Kazakov, Evolving design genes in space layout problems, Artificial Intelligence in Engineering 12 (3) (1998) 163-176.

[39] J. Kämpf, D. Robinson, Optimisation of building form for solar energy utilization using constrained evolutionary algorithms, Energy and Buildings 42 (6) (2010) 807-814.

[40] W. Wang, H. Rivard, R. Zmeureanu, Floor shape optimisation for green building design, Advanced Engineering Informatics 20 (2006) 363-378.

[41] M. Turrin, P. Buelow, R. Stouffs, Design explorations of performance driven geometry in architectural design using parametric modeling and genetic algorithms, Advanced Engineering Informatics 25 (2011) 656-675.

[42] J. Wright, M. Mourshed, Geometric optimisation of fenestration, in: IBPSA: 11th International Building Performance Simulation Association Conference, Glasgow, UK, 2009, http://www.ibpsa.org/proceedings/ BS2009/BS09_0920_927.pdf (accessed 22.01.2012).

[43] L. Caldas, L. Norford, A design optimisation tool based on a genetic algorithm, Automation in Construction 11 (2) (2002) 173-184.

[44] L. Caldas, et al., A design optimisation tool based on a genetic algorithm, Automation in Construction 11 (2) (2002) 173-184.

[45] L. Caldas, L. Norford, Shape generation using Pareto genetic algorithms: integrating conflicting design objectives in low-energy architecture, International Journal of Architectural Computing 1 (4) (2003) 503-515.

[46] L. Caldas, GENE_ARCH: an evolution-based generative design system for sustainable architecture, Lecture Notes in Computer Science 4200 (2006) 109.

[47] F. Flager, B. Welle, P. Bansal, G. Soremekun, J. Haymaker, Multidisciplinary process integration and design optimisation of a classroom building, ITcon 14 (2008) 595-612, http://www.stanford.edu/group/ CIFE/online.publications/TR175.pdf (accessed 1.06.2012).

[48] P. Geyer, Component-oriented decomposition for multidisciplinary design optimisation in building design, Advanced Engineering Informatics 23 (1) (2009) 12-31.

[49] K. Suga, S. Kato, K. Hiyama, Structural analysis of Pareto-optimal solution sets for multi-objective optimisation: an application to outer window design problems using multiple objective genetic algorithms, Building and Environment 45 (2010) 1144-1152.

[50] G. Rapone, O. Saro, Optimisation of curtain wall facades for office buildings by means of PSO algorithm, Energy and Buildings 45 (2011) (2012) 189-196.

[51] S. Attia, et al. (2012a) Simulation-based decision support tool for early stages of zero-energy building design, energy and buildings. Available online 10 February 2012, ISSN 0378-7788, 10.1016/j.enbuild.2012.01.028.

[52] S. Torres, Y. Sakamoto, Facade design optimisation for daylight with a simple genetic algorithm, in: Proceedings of Building Simulation, Beijing, 2007.

[53] M. Andersen, S. Kleindienst, L. Yi, J. Lee, M. Bodart, B. Cutler, An intuitive daylighting performance analysis and optimisation approach, Building Research and Information 36 (6) (2008) 593-607.

[54] A. Mahdavi, Simulation-based control of building systems operation, Building and Environment 36 (6) (2001) 789-796.

[55] A. Mahdavi, B. Spasojevic, K. Brunner, Elements of a simulation-assisted daylight-responsive illumination systems control in buildings, in: Building Simulation 2005, Ninth International IBPSA Conference, 15-18 August, Montreal, 2005, pp. 693-699.

[56] A. Mahdavi, C. Pröglhöf, in: Building Simulation (2005), Ninth International IBPSA Conference, 15-18 August, Montreal, Canada, A model-based method for the integration of natural ventilation in indoor climate systems operation (2005) 685-692.

[57] L. Stephan, A. Bastide, E. Wurtz, B. Souyri, Ensuring desired natural ventilation rate by means of optimized openings, in: Proc. of the 11-th IBPSA Conference, Glasgow, Scotland, 2009, pp. 2282-2288.

[58] H. Jedrzejuk, W. Marks, Optimisation of shape and functional structure of buildings as well as heat source utilization example, Building and Environment 37 (12) (2002) 1249-1253.

[59] J. Wright, V. Hanby, The formulation, characteristics, and solution of HVAC system optimized design problems, ASHRAE Transactions 93 (2) (1987) 2133-2145.

[60] J. Wright, HVAC optimisation studies: sizing by genetic algorithm, Building Services Engineering Research and Technology 17 (1) (1996) 7-14.

[61] Y. Asiedu, et al., HVAC Duct system design using genetic algorithms, HVAC\&R Research 6 (2) (2000) 149-173.

[62] L. Caldas, L. Norford, Genetic algorithms for optimisation of building envelopes and the design and control of HVAC systems, Journal of Solar Energy Engineering 125 (2003) 343-351.

[63] K. Fong, V. Hanby, et al., HVAC system optimisation for energy managemen by evolutionary programming, Energy \& Buildings 38 (3) (2006) 220-231.

[64] W. Huang, N. Lam, Using genetic algorithms to optimize controller parameters for HVAC systems, Energy and Buildings 26 (1997) 277-282.

[65] S. Wang, X. Jin, Model-based optimal control of VAV air-conditioning system using genetic algorithm, Building and Environment 35 (2000) 471-487.

[66] T. Chow, G. Zhang, et al., Global optimisation of absorption chiller system by genetic algorithm and neural network, Energy and Buildings 34 (2002) 103-109.

[67] J. Clarke, et al., Simulation-assisted control in building energy management systems, Energy and Buildings 34 (2002) (2002) 933-940.

[68] D. Kolokotsa, et al., Genetic algorithms optimizedfuzzy controller for the indoor environmental management in buildings implemented using PLC and local operating networks, Engineering Applications of Artificial Intelligence 15 (2002) 417-428.

[69] K. Fong, V. Hanby, T. Chow, Optimisation of MVAC systems for energy management by evolutionary algorithm, Facilities 21 (10) (2003) 223-232.

[70] N. Nassif, S. Kajl, R. Sabourin, Two-objective on-line optimisation of supervisory control strategy, Building Service Engineering 25 (3) (2004) 241-251.

[71] N. Nassif, S. Kajl, R. Sabourin, Evolutionary algorithms for multi-objective optimisation in HVAC system control strategy, in: Processing NAFIPS '04. IEEE Annual Meeting of the Fuzzy Information, vol. 1(1), 2004, pp. 51-56, http://ieeexplore.ieee.org/stamp/stamp.jsp?arnumber=01336248 (accessed 25.01.2012).

[72] N. Nassif, K. Stainslwa, R. Sabourin, Optimisation of HVAC control system strategy using two-objective genetic algorithm, HVAC\&R Research 11 (3) (2005) 459-486.

[73] M. Kummert, P. Andre, Simulation of a model-based optimal controller for heating systems under realistic hypothesis, in: Proceedings of the 9th IBPSA Conference, Building Simulation 2005, IBPSA, 2005.

[74] M. Mossolly, K. Ghali, N. Ghaddar, Optimal control strategy for a multi-zone air conditioning system using a genetic algorithm 34 (1) (2009) 58-66.

[75] W. Lee, Y. Chen, Y. Kao, Optimal chiller loading by differential evolution algorithm for reducing energy consumption, Energy and Buildings 43 (2-3)(2011) 599-604.

[76] U. Diwekar, I. Grossman, E. Rubin, An MINLP process synthesizer for sequential modular simulator, Industrial \& Engineering Chemical Research 31 (1992) 313.

[77] J. Wright, et al., Evolutionary synthesis of HVAC system configurations: algorithm development (RP-1049), HVAC\&R Research 14 (1) (2008) 33-55.

[78] G. Henze, et al., Experimental analysis of model-based predictive optimal control for active and passive building thermal storage inventory, HVAC\&R Research 11 (2) (2005) 189-214.

[79] G. Henze, M. Krarti, U.S. Department of Energy Cooperative Agreement DEFC-26-01NT41255, Predictive Optimal Control of Active and Passive Building Thermal Storage Inventory, Final Report. U.S. Department of Energy Information Bridge. http://www.osti.gov/servlets/purl/894509-GH9Mqf/, 2005.

[80] S. Liu, G. Henze, Calibration of building models for supervisory control of commercial buildings, in: Proceedings of the 9th International Building Performance Simulation Association (IBPSA) Conference 2005, Montreal, Canada, 2005.

[81] S. Liu, G. Henze, Experimental analysis of simulated reinforcement learning control for active and passive building thermal storage inventory. Part 1: theoretical foundation, Energy and Buildings 38 (2) (2006) 142-147.

[82] M. Wetter, J.Wright, Comparison of a generalized pattern search and a genetic algorithm optimisation method, in: Proceedings of the 8th International IBPSA Conference, Eindhoven, Netherlands, 2003, pp. 1401-1408.

[83] J. Wright, A. Alajmi, The robustness of genetic algorithms in solving unconstrained building optimisation problems, in: Proceedings of the 7th IBPSA Conference: Building Simulation, 15-18 August, Montréal, Canada, 2005, pp. 1401-1408.

[84] R. Pardo, et al. Building envelope optimisation. 12èmes Journées Internationales de Thermique, Tanger, Maroc, 2005.

[85] A. Hasan, M.Vuolle, K. Siren, Minimisation of life cycle cost of a detached house using combined simulation and optimisation, Building and Environment 43 (12) (2008) 2022-2034. 
[86] M. Palonen, A. Hasan, K. Siren, A genetic algorithm for optimisation of building envelope and HVAC system parameters, in: IBPSA 2009, 121th International IBPSA Conference, Glasgow, UK, 2009.

[87] M. Hamdy, A. Hasan, K. Siren, Combination of optimisation algorithms for a multi-objective building design problem, in: IBPSA: 11th International Building Performance Simulation Association Conference, Glasgow, UK, 2009, http://www.ibpsa.org/proceedings/BS2009/BS09_0173_179.pdf (accessed 10.01.2012)

[88] M. Hamdy, A. Hasan, K. Sirén, Optimum design of a house and its HVAC systems using simulation-based optimisation, International Journal of LowCarbon Technologies 5 (3) (2010) 120-124.

[89] Y. Bichiou, M. Krarti, Optimisation of envelope and HVAC systems selection for residential buildings, Energy and Buildings 43 (12) (2011) 3373-3382.

[90] M. Palonen, A. Hasan, K. Siren, A genetic algorithm for optimisation of building envelope and HVAC system parameters, in: Proc. of the 11th IBPSA Conference, Glasgow, Scotland, 2001.

[91] J. Wright, R. Farmani, The simultaneous optimisation of building fabric construction, HVAC system size, and the plant control strategy, in: Proceedings of the 7th IBPSA Conference: Building Simulation, vol. 2, Rio de Janeiro, Brazil, 2001, pp. 865-872.

[92] J. Wright, H. Loosemore, R. Farmani, Optimisation of building thermal design and control by multicriterion genetic algorithm, Energy \& Buildings 34 (9) (2002) 959-972.

[93] A. Brownlee, J. Wright, Solution analysis in multi-objective optimisation, in: Proc. Building Simulation and Optimisation (BSO12), IBPSA-England, Loughborogh University, UK, 2012.

[94] G. Verbeeck, H. Hens, Life cycle optimisation of extremely low energy dwellings, Journal of Building Physics 31 (2007) 143.

[95] D. Christina, et al., A multi-objective decision model for the improvement of energy efficiency, Energy 35 (2010) 5483-5496.

[96] C. Diakaki, et al., A multi-objective decision model for the improvement of energy efficiency, Energy 35 (12) (2010) 5483-5496.

[97] M. Hamdy, A. Hasan, K. Siré, A Multi-stage Optimisation Method for CostOptimal nearly-Zero-Energy Building Solutions in Line with the EPBD-Recast 2010, Energy and Buildings 56 (1) (2013) 189-203.

[98] M. Hamdy, M. Palonen, A. Hasan. Implementation of Pareto-Archive NSGAII Algorithms to a Nearly-Zero-Energy Building Optimisation Problem, In: BSO12 IBPSA-England, 10-11 September, Loughborogh University, UK, (2012 181-187).

[99] L. Caldas. An evaluation based generative design system: using adaptation to shape architectural form. PhD Thesis. MIT Press, 2001.

[100] T. Nielsen. Optimisation of buildings with respect to energy and indoor environment. PhD Dissertation. Technical University of Denmark, 2002. http://www.byg.dtu.dk/upload/institutter/byg/publications/rapporter/bygr036.pdf (accessed 22.01.2012).

[101] M. Wetter. PhD Dissertation. University of California at Berkeley, 2004. http://simulationresearch.lbl.gov/wetter/download/mwdiss.pdf (accessed 15.01.2012).

[102] W. Wang. A simulation-based optimisation system for green building design. PhD Thesis. Concordia University, Montreal, Quebec, 2005. http://spectrum.library.concordia.ca/8272/1/NR04054.pdf $\quad$ (accessed 22.01.2011)

[103] F. Pedersen. A method for optimizing the performance of buildings. PhD Dissertation, Technical University of Denmark, 2007. http://www.mek.dtu.dk/ Forskning/Publikationer/2008-2001.aspx?lg=showcommon\&id=196117 (accessed 22.01.2012).

[104] G. Verbeeck. Optimisation of extremely low energy residential buildings. Ph D Thesis, Department of Civil Engineering, Catholic University of Leuven, Belgium, 2007b. http://bwk.kuleuven.be/bwf/PhDs/PhDVerbeeck (accessed 22.01.2012).

[105] R. Choudhary. A hierarchical design optimisation framework for simulation based architectural design. PhD Dissertation, University of Michigan, USA, 2004

[106] C. Hopfe. Uncertainty and sensitivity analysis in building performance simulation for decision support and design optimisation. PhD Dissertation, Eindhoven University, 2009.

[107] V. Congradac, F. Kulic, HVAC system optimisation with $\mathrm{CO}_{2}$ concentration control using genetic algorithms, Energy and Buildings 41 (2009) (2009) 571-577.

[108] F. Talbourdet, et al., Stochastic optimisation based approach for efficient building design, in: Proceedings of the CIB W78-W102: International Conference, 26-28 October, Sophia Antipolis, France, 2011, http://2011-cibw078w102.cstb.fr/papers/Paper-39.pdf (accessed 22.01.2012).

[109] K. Mela, T. Tiainen, M. Heinisuo, Comparative study of multiple criteria decision making methods for building design, Advanced Engineering Informatics 26 (4) (2012) 716-726.

[110] E. Tresidder, Y. Zhang, A. Forrester, Optimisation of low-energy building design using surrogate models, in: Proceedings of Building Simulation: 12th Conference of International Building Performance Simulation Association, 14-16 November, Sydney, 2011, http://www.bounceinteractive.com/ bs2011/bs2011/pdf/P_1374.pdf (accessed 22.01.2012).

[111] M. Hamdy, A. Hasan, K. Siren, Impact of adaptive thermal comfort criteria on building energy use and cooling equipment size using a multi-objective optimisation scheme, Energy and Buildings 43 (2011) 2055-2067.

[112] M. Mourshed, D. Kelliher, M. Keane, ArDOT: a tool to optimise environmental design of buildings, in: Proc: Eighth IBPSA Conference: Building
Simulation 2003, Eindhoven, Netherlands, 2003, http://zuse.ucc.ie/iruse/ papersnew/ibpsa2003monjur.pdf (accessed 22.01.2012).

[113] G. Kayo, R. Ooka, Building energy system optimisations with utilization of waste heat from cogenerations by means of genetic algorithm, Energy and Buildings 42 (7) (2010) 985-991.

[114] A. Antoniou, L. Wu-Sheng, Practical Optimisation: Algorithms and Engineering Applications, Springer Science+Business Media, LLC, New York, USA, 2007.

[115] R. Hooke, T. Jeeves, Direct search solution of numerical and statistical problems, Journal of the ACM 8 (2) (1961) 212-229.

[116] M. Emmerich, C. Hopfe, R. Marijt, J. Hensen, C. Struck, L. Stoelinga, Evaluating optimisation methodologies for future integration in building performance tools, in: Proceedings of the 8th Int. Conf. on Adaptive Computing in Design and Manufacture (ACDM), Bristol, 2008, pp. 1-7.

[117] M. Emmerich, J. Zhou, M. Özdemir. TOP - a toolbox for the optimisation of parameters. Lehrstuhl fuer Systemanalyse, University of Dortmund. http://www.liacs.nl/ emmerich/topman.pdf, 2003 (accessed 12.06.2012).

[118] Z. Michalewicz, G. Nazhiyath, M. Michalewicz, A note on usefulness of geometrical crossover for numerical optimisation problems, in: Proceedings of the 5th Annual Conference on Evolutionary Programming, 29 February-3 March, San Diego, CA, MIT Press, Cambridge, MA, 1996, pp. 305-312.

[119] P. Collet, J. Rennard, Stochastic optimisation algorithms, in: J.P. Rennard (Ed.), Handbook of Research on Nature Inspired Computing for Economics and Management, IGR, Hershey, 2006.

[120] N. Metropolis, A. Rosenbluth, M. Rosenbluth, A. Teller, E. Teller, Equation of State Calculation by Fast Computing Machines, Journal of Chemical Physics 21 (1953) 1087-1091.

[121] S. Kirkpatrick, C. Gelatt, M. Vecchi, Optimisation by simulated annealing, Science 220 (4598) (1983) 671-680, http://home.gwu.edu/ $\sim$ stroud/classics/KirkpatrickGelattVecchi83.pdf (accessed 10.01.2011).

[122] V. Cerny, Thermodynamical approach to the traveling salesman problem: an efficient simulation algorithm, Journal Optimisation Theory and Application 45 (1985) 41-51.

[123] F. Glover, Tabu Search, Kluwer Academic Publishers Norwell, MA, USA (1997) ISBN:079239965X.

[124] A. Colorni, M. Dorigo, V. Maniezzo, Distributed optimisation by ant colonies, in: Proceedings of Ecal91 - European Conference on Artificial Life, Elsevier Publishing, Paris, France, 1991, pp. 134-142, http://iridia ulb.ac.be/pub/mdorigo/conferences/IC.06-ECAL92.pdf (accessed 1.06.2012).

[125] R. Eberhart, J. Kennedy, Particle swarm optimisation, in: IEEE International Conference on Neural Networks, vol. IV, Perth, Australia, 1995, pp. 1942-1948.

[126] J.H. Holland, Adaptation in Natural and Artificial Systems, The University of Michigan Press, Ann Arbor, 1975.

[127] D. Goldberg, Genetic Algorithms in Search, Optimisation and Machine Learning, Addison Wesley, Boston, MA, USA, 1989.

[128] K. Deb, A. Pratap, S. Agarwal, T. Meyarivan, A fast and elitist multiobjective genetic algorithm: NSGA-II IEEE, Transactions on Evolutionnary Computation 6 (2) (2002) 182-197

[129] R. Baldock, K. Shea, D. Eley, Evolving optimized braced steel frameworks for tall buildings using modified pattern, in: 2005 International conference on computing in civil engineering (ASCE 2005), vol. 60, Cancun, Mexico, 2005.

[130] K. Shea, A. Sedgwick, G. Antonuntto, Multicriteria optimization of paneled building envelopes using ant colony optimization, Intelligent Computing in Engineering and Architecture (2006) 627-636

[131] A. Kusiak, G. Xu, F. Tang, Optimisation of an HVAC system with a strength multi-objective particle-swarm algorithm, Energy 36 (10)(2011) 5935-5943.

[132] M. Mitchell, An Introduction to Genetic Algorithm, MIT Press, Cambridge, MA, 1997.

[133] L. Chambers, The Practical Handbook of Genetic Algorithms, Chapman \& Hall/CRC, New York, USA (2001).

[134] M. Manzan, F. Pinto, O. Saro. Thermal comfort and energy saving optimisation for HVAC systems with night ventilation cooling, pp. 175-180, 2006

[135] L. Caldas, Generation of energy-efficient architecture solutions applying GENE_ARCH: an evolution-based generative design system, Advanced Engineering Informatics 22 (1) (2008) 59-70 http://www.stanford.edu/group/ CIFE/online.publications/TR175.pdf

[136] L. Magnier, F. Haghighat, Multiobjective optimisation of building design using TRNSYS simulations, genetic algorithms, and artificial neural network, Building and Environment 45 (3) (2010) 739-746.

[137] E. Zitzler, K. Deb, L. Thiele, Comparison of multiobjective evolutionary algorithms: empirical results, Evolutionary Computation 8 (2) (2000) 173-195.

[138] P. Hoes, M. Trcka, J. Hensen, B. Bonnema, Optimizing building designs using a robustness indicator with respect to user behavior, in: Building Simulation Proceedings of the 12th Conference of the International Building Performance Simulation Association, 2011, pp. 1710-1717.

[139] R. Loonen, M. Trcka, J. Hensen, Exploring the potential of climate adaptive building shells, in: Building Simulation 2011: 12th Conference of International Building Performance Simulation Association, 14-16 November, 2011, pp. 2148-2155.

[140] M. Wetter. Design Optimisation with GenOpt. Building Energy Simulation User News 21, 2000.

[141] J. Nelder, R. Mead, A simplex method for function minimization, The Computer Journal 7 (4) (1965) 308-313.

[142] J. Nelder, R. Mead, Simplex method for function minimization, The Computer Journal 7 (4) (1965) 308-313. 
[143] M. Wetter. GenOpt ${ }^{\circledR}$ Generic Optimisation Program-User Manual Version 3.0.0. Simulation Research Group Building Technologies Department Environmental Energy Technologies Division Lawrence Berkeley National Laboratory Berkeley, CA, USA, 2009.

[144] B. Coffey. A development and testing framework for simulation-based supervisory control with application to optimal zone temperature ramping demand response using a modified genetic algorithm. Master Thesis. Concordia University, Quebec, Canada, 2008.

[145] B. Coffey, F. Haghighat, E. Morofsky, E. Kutrowski, A software framework for model predictive control with GenOpt, Energy and Buildings 42 (7) (2010) 1084-1092.

[146] N. Djuric, G. Huang, V. Novakovic, Data fusion heat pump performance estimation, Energy and Buildings 43 (2-3) (2011) 621-630.

[147] N. Djuric, V. Novakovic, J. Holst, Z. Mitrovic, Optimisation of energy consumption in buildings with hydronic heating systems considering thermal comfort by use of computer-based tools, Energy and Buildings 39 (4) (2007) 471-477.

[148] D. Jacob, S. Burhenne, A. Florita, G. Henze, Optimizing building energy simulation models in the face of uncertainty, in: Fourth National Conference of IBPSA-USA, 11-13 August, New York City, NY, 2010.

[149] M. Kummert, Using GenOpt with TRNSYS16 and Type 56, ESRU, University of Strathclyde, Glasgow, UK, 2007.

[150] L. Magnier, L. Zhou, F. Haghighat, Multiobjective optimisation of building design using genetic algorithm and artificial neural network, in: Proceedings of eSim Conference, Quebec, Canada, 2008.

[151] L. Magnier, L. Zhou, F. Haghighat, Multiobjective optimisation of building design using TRNSYS simulations, genetic algorithm, Artificial Neural Network, Building and Environment 45 (3) (2009) 739-746.

[152] C. Park, G. Augenbroe, N. Sadegh, M. Thitisawat, T. Messadi, Real-time optimisation of a double-skin façade based on lumped modeling and occupant preference, Building and Environment 39 (8) (2004) 939-948, ISSN 03601323, 10.1016/j.buildenv.2004.01.018.

[153] G. Henze, C. Felsmann, G. Knabe, Evaluation of optimal control for active and passive building thermal storage, International Journal of Thermal Sciences 43 (2) (2004) 173-183, ISSN 1290-0729, 10.1016/j.ijthermalsci.2003.06.001.

[154] S. Xing, Design optimisation of insulation usage and space conditioning load using energy simulation and genetic algorithm, Energy 36 (3) (2011) 1659-1667.

[155] P. Ellis, B. Griffith, et al. (2006). Automated multivariate optimisation tool for energy analysis, Citeseer.
[156] L. Herrmann, M. Deru, J. Zhai, Evaluating energy performance and improvement potential of china office buildings in the hot humid climate against U.S. reference buildings, in: 1st International High Performance Buildings Conference, 12-15 July, Purdue University West Lafayette, IN, 2010.

[157] N. Long, A. Hirsch, C. Lobato, D. Macumber, Commercial building design pathways using optimisation analysis, in: ACEEE Summer Study, 15-20 August, Pacific Grove, CA, 2010.

[158] C. Christensen, et al., A sequential search technique for identifying optima building designs on the path to zero net energy, in: Proceedings of the Solar 2004. American Solar Energy Society, vol. 13, 2004, p. 14.

[159] DOE, U.S., 2010. Building America Homepage. http://www.eere.energy.gov/ buildings/building_america/ (accessed 1.06.2012).

[160] Winkelmann, et al. DOE-2 supplement, Version 2.1E. Technical Report LBL-34947, Lawrence Berkeley National Laboratory, Berkeley, CA, USA (1993).

[161] S. Klein, J. Duffie, W. Beckman, TRNSYS - a transient simulation program, ASHRAE Transactions 82 (1) (1976) 623-633.

[162] R. Anderson, C. Christensen, S. Horowitz. Program design analysis using BEopt (building energy optimisation) software: defining a technology pathway leading to new homes with zero peak cooling demand, ACEEE summer study on energy efficiency in buildings. http://www.eceee.org/conference proceedings/ACEEE_buildings/2006/Panel_2/p2_3/paper, 2006 (accessed 1.06.2012)

[163] T. Givler. Evaluating optimal building designs for Habitat for Humanity using BEopt (Building Energy Optimisation) software. MSc Thesis. University of Colorado, Boulder, 2006, $161 \mathrm{pp}$.

[164] B. Polly, M. Gestwick, M. Bianchi, R. Anderson, S. Horowitz, C. Christensen, R. Judkoff. A method for determining optimal residential energy efficiency retrofit packages national renewable energy laboratory, 2011.

[165] S. Attia. Optimisation for zero energy building design: interviews with twenty eight international experts, Architecture et Climat, Louvain La Neuve, Université catholique de Louvain. http://www-climat.arch.ucl.ac.be/s_attia/ Attia_Optimisation\%20Interviews_2012.pdf, 2012 (accessed 1.06.2012).

[166] E. Hale, N. Long, Enumerating a Diverse Set of Building Designs Using Discrete Optimisation, SimBuild, New York, NY, 2010, pp. 15-19.

[167] C. Hopfe, J. Hensen, Uncertainty analysis in building performance simulation for design support, Energy and Buildings 43 (10) (2011) 27982805 doi:10.1016/j.enbuild.2011.06.034. 